\title{
Measuring the Atlantic Meridional Overturning Circulation at $26^{\circ} \mathrm{N}$
}

\author{
G.D. McCarthy ${ }^{\text {a,* }}$, D.A. Smeed ${ }^{\text {a }}$, W.E. Johns ${ }^{\text {b }}$, E. Frajka-Williams ${ }^{c}$, B.I. Moat ${ }^{\text {a }}$, D. Rayner ${ }^{\text {a }}$, M.O. Baringer ${ }^{\text {d }}$, \\ C.S. Meinen ${ }^{\mathrm{d}}$, J. Collins ${ }^{\mathrm{e}}$, H.L. Bryden ${ }^{\mathrm{c}}$
}

${ }^{a}$ National Oceanography Centre, European Way, Southampton SO14 3ZH, UK

${ }^{\mathrm{b}}$ University of Miami, Rosentiel School of Marine and Atmospheric Science, 4600 Rickenbacker Causeway, Miami, FL, USA

${ }^{\mathrm{c}}$ National Oceanography Centre, University of Southampton, Waterfront Campus, Southampton SO14 3ZH, UK

${ }^{\mathrm{d}}$ Atlantic Oceanographic and Meteorological Laboratory, PHOD, 4301 Rickenbacker Causeway, Miami, FL 33149, USA

e British Oceanographic Data Centre, National Oceanography Centre, European Way, Southampton SO14 3ZH, UK

\section{A R T I C L E I N F O}

\section{Article history:}

Received 11 May 2014

Received in revised form 9 October 2014

Accepted 12 October 2014

Available online 18 October 2014

\begin{abstract}
A B S T R A C T
The Atlantic Meridional Overturning Circulation (AMOC) plays a key role in the global climate system through its redistribution of heat. Changes in the AMOC have been associated with large fluctuations in the earth's climate in the past and projections of AMOC decline in the future due to climate change motivate the continuous monitoring of the circulation. Since 2004, the RAPID monitoring array has been providing continuous estimates of the AMOC and associated heat transport at $26^{\circ} \mathrm{N}$ in the North Atlantic. We describe how these measurements are made including the sampling strategy, the accuracies of parameters measured and the calculation of the AMOC. The strength of the AMOC and meridional heat transport are estimated as 17.2 Sv and 1.25 PW respectively from April 2004 to October 2012. The accuracy of ten day (annual) transports is $1.5 \mathrm{~Sv}(0.9 \mathrm{~Sv})$. Improvements to the estimation of the transport above the shallowest instruments and deepest transports (including Antarctic Bottom Water), and the use of the new equation of state for seawater have reduced the estimated strength of the AMOC by 0.6 Sv relative to previous publications. As new basinwide AMOC monitoring projects begin in the South Atlantic and sub-polar North Atlantic, we present this thorough review of the methods and measurements of the original AMOC monitoring array.
\end{abstract}

Crown Copyright @ 2014 Published by Elsevier Ltd. All rights reserved.

\section{A review of measuring the $A M O C$}

The world's oceans are a major part of the heat engine of the global climate system, moving heat, together with the atmosphere, from equatorial regions to the high latitudes. The South Atlantic is the exception in this picture of heat redistribution, transporting heat northwards (Bennett, 1978) across the equator as part of the Atlantic Meridional Overturning Circulation (AMOC). The heat released by the ocean over the North Atlantic contributes to the relatively mild climate of north western Europe (Seager et al., 2002) with the AMOC being responsible for the approximately $3{ }^{\circ} \mathrm{C}$ warmer temperatures on the northwestern European seaboard compared to similar maritime climates on the western seaboard of North America (Rhines et al., 2008).

Observation of the AMOC is quite challenging, requiring measurements that span a complete basin, so historically the observational record has been quite limited. There have been several reviews of AMOC observations focusing on aspects such as the

\footnotetext{
* Corresponding author.

E-mail address: gerard.mccarthy@noc.ac.uk (G.D. McCarthy).
}

history of observations (Warren and Wunsch, 1981; Mills, 2009), the representations, (Richardson, 2008) and the quantification (Longworth and Bryden, 2007) of the AMOC. Early estimates on the size of the deep circulation were based solely on property distributions. Sverdrup et al. (1942) estimated a $7 \mathrm{~Sv}\left(1 \mathrm{~Sv}=10^{6} \mathrm{~m}^{3} / \mathrm{s}\right)$ flow of deep water out of the North Atlantic and across the equator that could be traced southward through the South Atlantic and around the Southern Ocean. Swallow and Worthington (1957) made short term float trajectory observations in the deep western boundary current off South Carolina that supported the value of $7 \mathrm{~Sv}$ for the deep circulation. This value was maintained by Worthington (1976) in his influential summary of North Atlantic circulation.

Modern estimates for the size of the overturning circulation began with analyses of coast-to-coast hydrographic sections in the early 1980s (Bryden and Hall, 1980; Hall and Bryden, 1982; Roemmich and Wunsch, 1985). They found an overturning circulation of about $18 \mathrm{~Sv}$, contradicting the previous value of $7 \mathrm{~Sv}$, and a northward heat transport of $1.2 \mathrm{PW}\left(1 \mathrm{PW}=10^{15} \mathrm{~W}\right)$. Analysis of historical and modern hydrographic sections generally finds an Atlantic overturning circulation of the order of $18 \mathrm{~Sv}$ and its associated northward heat transport robustly positive. 
The idea that the overturning circulation has varied through the earth's history, with the precept that the ice ages had smaller overturning circulation (Broeker, 1991), combined with evidence in paleo proxies developed from ice cores that there had been decadal-to-centennial fluctuations in temperature of order $10^{\circ} \mathrm{C}$ (Dansgaard et al., 1993), made a compelling case that the overturning circulation should be monitored; firstly, to quantify its variability on sub-annual to interannual time scales and, secondly, to assess whether there might be long-term trends in the circulation and possibly identify tipping points where the circulation suddenly changed or stopped.

The paucity of observations contrasted sharply with the potential societal impacts of an AMOC slowdown when, using all five trans-Atlantic hydrographic sections available at $24^{\circ} \mathrm{N}$, Bryden et al. (2005) suggested that the AMOC had slowed by $30 \%$ since the late 1950s. During the ensuing controversy, it was frequently highlighted that very little was known about the variability of AMOC on shorter timescales and that the apparent slowdown could well have been encompassed within shorter timescale variations in the circulation.

By the turn of the millennium there was both scientific desire and societal need to monitor the overturning circulation. Observing System Simulation Experiments (OSSEs) by Hirschi et al. (2003) and Baehr et al. (2004) demonstrated that an array of sparse moorings could monitor the AMOC in an OGCM using geostrophic dynamics. A joint UK/US proposal to build and deploy a test monitoring system for the AMOC for 4 years was endorsed after peer review by both the UK Natural Environment Research Council (NERC) and US National Science Foundation (NSF) (Srokosz, 2004).

Marotzke et al. (1999) had proposed monitoring the circulation at $29^{\circ} \mathrm{N}$. This was motivated by the common definition of the AMOC in ocean general circulation models (OGCM) as the maximum value of the overturning transport streamfunction in latitude-depth space, which generally occurs near $29^{\circ} \mathrm{N}$. However, the large resources necessary to define and measure the Gulf Stream flow across $29^{\circ} \mathrm{N}$ were not economical: $26.5^{\circ} \mathrm{N}$, where the Gulf Stream is confined to the Florida Straits and has been monitored continuously since 1982 (Baringer and Larsen, 2001), was a much more pragmatic location.

The project to monitor the Atlantic Meridional Overturning Circulation at $26.5^{\circ} \mathrm{N}$ has been known as the RAPID/MOCHA/WBTS program consisting of the NERC funded RAPID family of programmes, the NSF funded Meridional Overturning Circulation Heat-flux Array project, and the National Oceanic and Atmospheric Administration (NOAA) funded Western Boundary Time Series project. Here we will refer to it simply as RAPID. The trans-basin array began in March 2004 and has continued up to the present.

At a fundamental level, RAPID monitoring is based on geostrophic dynamics. For averaging time scales longer than a few days, the zonal momentum balance holds between the zonal pressure gradient and the Coriolis force associated with the northward current:

$\frac{\partial p}{\partial x}=\rho f v$

where $v$ is northward velocity, $\rho$ is density of sea water and $f$ is the Coriolis parameter. Geostrophic balance in the zonal momentum balance works to high accuracy right up to the eastern and western boundaries even for strong boundary currents, as shown by Beal and Bryden (1999) for the Agulhas Current, and over the full depth range. In a scaling analysis framework, there is no other term in the zonal momentum balance within two orders of magnitude of the zonal pressure gradient and Coriolis force.

The second remarkable feature of the geostrophic balance is that it provides accurate zonal integrals of the northward mass transport. At constant latitude, the Coriolis parameter is a constant, so the geostrophic balance can be zonally integrated between any two points and the difference in pressure, $\Delta p$, divided by $f$ equals the zonally integrated northward velocity:

$\frac{\Delta p}{f \rho}=\int v d x$

So for an ocean basin with vertical walls and a flat bottom, if the pressure can be measured at the eastern boundary and the western boundary then the pressure difference divided by the constant $f$ equals the zonally integrated northward flow and no further measurements are necessary.

On time scales of a few days or more the acceleration in the vertical momentum equation can be neglected and the vertical profile of pressure, relative to a reference level, can be calculated by vertically integrating the hydrostatic equation,

$\int \frac{1}{\rho} d p=\int \alpha d p=-\int g d z=\int d \boldsymbol{\Phi}$,

where $g$ is gravitational acceleration, $\alpha$ is specific volume anomaly and $\boldsymbol{\Phi}$ is dynamic height. From hydrographic stations at the boundaries, the pressure difference across the basin, and hence the vertical structure of the horizontally integrated northward flow relative to a reference level, can be calculated. Combining Eqs. (1.2) and (1.3) allows us to estimate the transport between two hydrographic stations at the east and west of a zonal section, relative to a reference level transport, as:

$T_{\text {int }}(z)=\int\left(v-v_{r}\right) d x=\frac{1}{f}\left(\Phi_{e}(z)-\Phi_{w}(z)\right)$,

where $T_{\text {int }}$ is the internal geostrophic transport relative to an unknown reference level velocity, $v_{r}$, and $\Phi$ is the dynamic height anomaly on the eastern and western boundaries. Dynamic height as a function of depth is equal to the sum of dynamic height anomaly and the standard geometric separation. As dynamic height anomaly is the quantity calculated here, this is what will be referred to in the text-equally dynamic height could be used in Eq. (1.4).

For RAPID, the key measurements are at the eastern and western boundaries of the Atlantic Ocean at $26^{\circ} \mathrm{N}$ and on either side of the mid-Atlantic ridge (Fig. 1.1). Because the boundary is not vertical but sloping, several moorings at different locations on the slope are combined to form a single profile (Further details in the following section). The resulting time series of density profiles at the eastern and western boundaries are vertically integrated to produce dynamic height anomaly profiles from which the internal geostrophic transport is calculated.

This internal geostrophic transport is then combined with the Gulf Stream transport through the Florida Straits monitored by a submarine cable, flow over the Bahamas escarpment west of $76.75^{\circ} \mathrm{W}$ measured by current meters (Johns et al., 2008), and the wind-driven surface layer Ekman transport and adjusted so that the net transport across the whole section is zero to define the vertical structure of the overall meridional flow across the $26^{\circ} \mathrm{N}$ section from Florida to Africa. The transport streamfunction is then described by the integral of the transport per unit depth:

$\Psi(t, z)=\int T(t, z) d z$

where $\Psi$ is the overall transport streamfunction. The maximum of this streamfunction is defined as the strength of the AMOC at this latitude.

As described, vertical profiles of geostrophic transports derived from dynamic height anomaly profiles are relative to an unknown reference level: the shape of the vertical profile is defined by the pair of hydrographic stations but the profile is subject to an offset, or reference level velocity, that is uniform in depth. RAPID uses mass conservation for the North Atlantic north of $26^{\circ} \mathrm{N}$ to define 

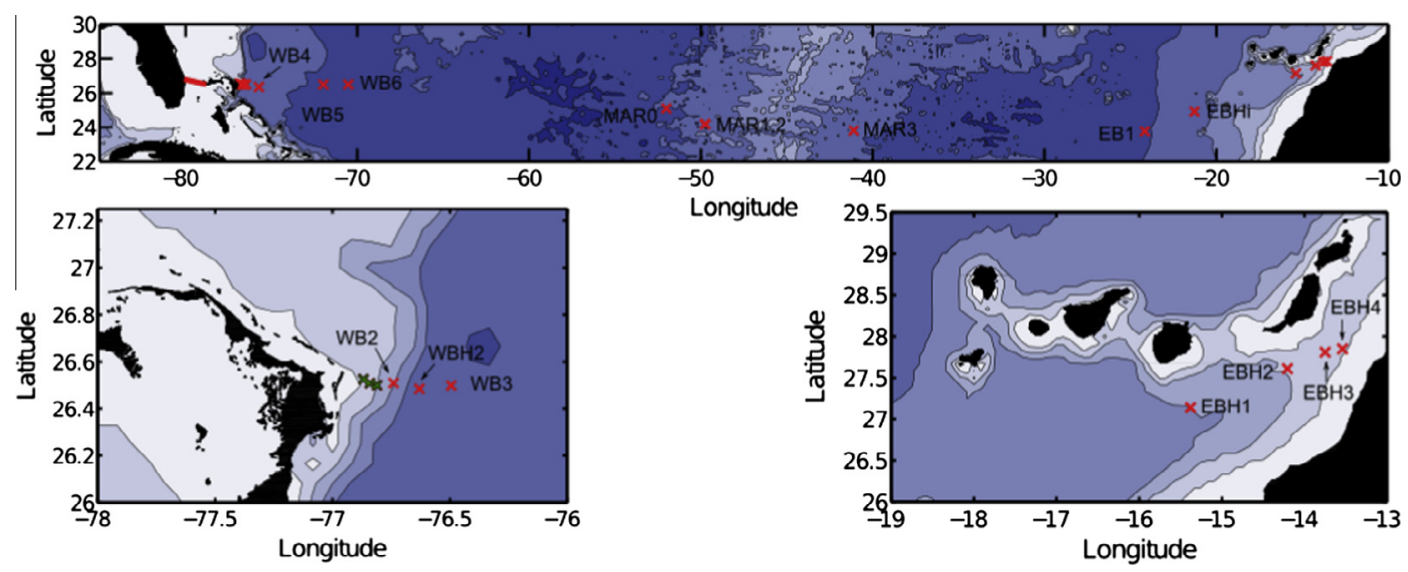

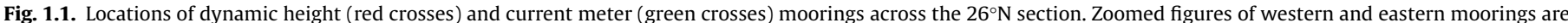

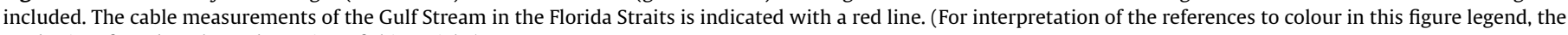
reader is referred to the web version of this article.)

the reference level velocity. The Atlantic north of $26^{\circ} \mathrm{N}$ is effectively a closed volume: at its northern boundary a small, order $1 \mathrm{~Sv}$ flow goes through the Bering Strait (Woodgate et al., 2005) and a net evaporation-precipitation-river inflow of less than $1 \mathrm{~Sv}$ enters across the land boundaries and air-sea interface (Baumgartner and Reichel, 1975). This volume conservation is a fundamental balance in the ocean. If $1 \mathrm{~Sv}$ was to flow into the Atlantic without flowing out again, the sea surface height (SSH) would be rising at a rate of centimetres per year. In fact, bottom pressure fluctuations at $26^{\circ} \mathrm{N}$ have a root mean square (rms) variability of around $1.5 \mathrm{~cm}$ indicative of the Atlantic basin filling and draining on the order of 5-10 days (Bryden et al., 2009). For constant sea level, the net flow across $26^{\circ} \mathrm{N}$ must be zero with a tolerance of order $1 \mathrm{~Sv}$. Kanzow et al. (2007) validated this assumption by showing that for bottom pressure measurements with averaging time scales longer than 10 days the mass balance between the upper level northward flow and deeper level southward flow holds. For these reasons, the reference level velocity for the mid-ocean geostrophic velocity profile is chosen so that the net northward flow of upper waters exactly balances the southward flow of deeper waters in the mid-ocean at each point in time.

The importance of the AMOC lies in the fact that it transports $90 \%$ of the ocean's meridional heat transport (MHT) at the latitude of $26.5^{\circ} \mathrm{N}$ (Johns et al., 2011). Estimates of MHT using hydrographic sections stretch back to the early 1980s (Bryden and Hall, 1980). Using the RAPID observations, Johns et al. (2011) produced time varying estimates of the MHT at $26.5^{\circ} \mathrm{N}$. The MHT is a more difficult quantity to estimate than the AMOC, since it involves the product of velocity and temperature, and thus in principle requires fully resolved velocity and temperature fields across the whole section. The approach to quantifying the MHT uses the construction suggested by Bryden and Imawaki (2001) by considering the overturning ('baroclinic' component in Bryden and Imawaki, 2001) and horizontal heat transport. As discussed in the previous paragraph, the net mass transport through the section ('barotropic' component in Bryden and Imawaki, 2001) is zero. Here the zero mass transport constraint is essential; only when the mass fluxes of these components balance and they are summed together do these temperature transports yield a meaningful heat transport value (Montgomery, 1974).

The measurements of the AMOC and the MHT from the RAPID array have had a large impact on understanding of the variability of the overturning circulation. The first year's measurements (Cunningham et al., 2007) showed a variable AMOC that encompassed, over a time period of a few weeks, the full variability seen in the Bryden et al. (2005) measurements. Kanzow et al. (2010) emphasised the large ( $7 \mathrm{~Sv}$ ) seasonal cycle in the AMOC at $26^{\circ} \mathrm{N}$. McCarthy et al. (2012) showed large variability (a 30\% drop) was possible on interannual timescales. Bryden et al. (2014) linked this downturn to the ocean influencing the atmosphere on shorter timescales than were previously thought possible. Recently, Smeed et al. (2014) have shown a multi-year decline in the AMOC, this estimate of a decline is far more robust than the Bryden et al. (2005) measurements due to the understanding of the variability of the AMOC that has been built up over the ten years of the RAPID project.

This paper is a detailed review of the trans-basin geostrophic measurements, calculations and errors that are the novel element of the RAPID array. We detail the utilisation of these measurements in the calculation of the AMOC and MHT. We also include several updates to the calculation of the AMOC described in Rayner et al. (2011) including:

- a detailed estimation of error estimates due to calibration and sampling,

- improved gridding procedure using a new seasonal climatology,

- improved surface extrapolation above the shallowest instrument,

- revised Antarctic Bottom Water strength and vertical structure,

- use of the new equation of state, TEOS-10.

And updates to the calculation of the MHT described in Johns et al. (2011) including:

- The use of a gridded climatology derived from RAPID moored and Argo temperature and salinity profiles to estimate the Ekman, eddy and mid-ocean heat transport.

The RAPID measurements have been used extensively for validation of model estimates of the AMOC (e.g. Xu et al., 2012; Blaker et al., 2014) and the MHT, (e.g. Haines et al., 2013; Msadek et al., 2013) therefore a detailed understanding of how the RAPID calculations are made is vital to understanding where discrepancies lie between models and observations. This relates to understanding how models fail to emulate observations but also where models can improve the observational analysis, for example Haines et al. (2013), highlighted areas that were undersampled or misinterpreted in the observational record. Finally, while RAPID was the first fully trans-basin AMOC continuous monitoring project, projects in the South Atlantic (South Atlantic MOC Basin-wide Array-SAMBA) (Meinen et al., 2013) and the sub-polar North Atlantic (Overturning in the Sub-polar North Atlantic 
Programme-OSNAP) are now underway and hence a review of the development of the original AMOC measurements and monitoring strategy at $26^{\circ} \mathrm{N}$ is timely.

This paper is arranged as follows. The following section focuses on the basin-wide internal geostrophic flow from dynamic height moorings. This includes several elements: the design of the array; a description of the locations, calibration, merging and gridding of the measurements; a discussion of improvements to the calculation of the shallowest transports and the deepest transports; and finally a description of the changes due to the new equation of state for seawater. Accuracies and errors are discussed in terms of their impact on the estimation of the AMOC. Errors of $\mathrm{O}(0.01 \mathrm{~Sv})$ and smaller are described as not significant: this will be shown to be of $\mathrm{O}(1 \%)$ of the accuracy of the AMOC calculation. In the next section, we combine the internal geostrophic flow with other components of the circulation at $26^{\circ} \mathrm{N}$ including the Gulf Stream and Ekman transport. The final two sections focus on the calculation of the AMOC and of the MHT are presented.

\section{The basin-wide geostrophic flow from dynamic height moorings}

\section{Design of the array}

Measuring the basinwide geostrophic transports with the RAPID array relies on measuring vertical profiles of temperature and salinity ${ }^{1}$ at the eastern and western boundaries at $26^{\circ} \mathrm{N}$ and where the bathymetry alters the pressure gradients on either side of the midAtlantic ridge. The mid-Atlantic ridge protrudes up to about 3800 dbar. Below this depth, we use moorings on either side of the ridge to estimate pressure gradients in the deep eastern and western basins. In practice, at $26^{\circ} \mathrm{N}$, the array of dynamic height moorings was designed to measure the geostrophic flow from $76.75^{\circ} \mathrm{W}$ to the African coast. West of $76.75^{\circ} \mathrm{W}$ to Abaco Island elements of the Antilles and deep western boundary currents are measured with current meters to capture this vigorous flow adjacent to and over the continental shelf (Johns et al., 2008). West of the Bahamas archipelago, the Gulf Stream at $26^{\circ} \mathrm{N}$ is confined to the Florida Straits, where it is monitored by cable measurements calibrated with regular ship sections since 1982 (Baringer and Larsen, 2001; Meinen et al., 2010).

The initial moored array deployed in 2004 consisted of 22 moorings with a total of 192 instruments (Rayner et al., 2005). In the configuration deployed in Autumn 2012, the array consisted of 19 moorings $^{2}$ and 22 landers, ${ }^{3}$ with a total of 252 instruments (McCarthy, 2012). Based on experience with the initial deployments some changes in the locations and design of the moorings have been made (Rayner and Kanzow, 2011). This has lead to a data return of $100 \%$ and $96 \%$ for the array as recovered in 2011 and 2012 respectively, compared to $73 \%, 91 \%$ and $85 \%$ for the recovery years 2005 , 2006 and 2007 respectively. The return rates for these years are high in comparison with recent results from other long-term operational moored arrays such as the TAO array in the Pacific (McPhaden et al., 2010).

The array was designed similar to the virtual arrays simulated by Hirschi et al. (2003) and Baehr et al. (2004) to monitor the AMOC in the ocean general circulation models OCCAM and FLAME respectively (Fig. 2.1) Within this overall array, we consider the three sub-arrays highlighted in Fig. 2.1: (A) the western boundary

\footnotetext{
1 'Salinity' means practical salinity in this text. Where absolute salinity is used it is referred to explicitly.

2 "Moorings" refers to wire/rope constructions with instruments that take measurements in the water column.

3 "Landers" refers to seafloor constructions equipped with bottom pressure recorders.
}

array, (D) the eastern boundary array and (B) the mid-Atlantic ridge array consisting of moorings on the western flank (marwest) and (C) eastern flank (mareast) of the ridge. A single hydrographic profile for each sub-array is constructed by horizontally merging the moorings, giving profiles from the shallowest instrument to 4820 dbar at marwest, the eastern and western boundaries, and, at mareast, from 3700 dbar to 4820 dbar. Dynamic height anomaly calculated at each of these locations is referenced to $4820 \mathrm{dbar}-$ the deepest standard measurement level. The transport profile is then proportional to the difference between each adjacent pair of merged dynamic height anomaly profiles, prior to adjustment for mass conservation.

To account for the mid-Atlantic ridge, transports deeper than the ridge crest at $3700 \mathrm{dbar}$ are the sum of the transports from the eastern boundary to mareast plus those from marwest to the western boundary. Shallower than the ridge crest, the transports are essentially the dynamic height difference between the eastern and western boundaries. The transports shallower than the ridge crest and those deeper than the ridge crest are adjusted so that there is no discontinuity at $3700 \mathrm{dbar}$. The mid-Atlantic ridge array is particularly important in resolving the mean northward flow between the western flank of the ridge at depths greater than the permeable height of the ridge (pressures greater than 3700 dbar) and the western boundary. If the mid-Atlantic ridge moorings are excluded, the calculated AMOC is overestimated by about $1.6 \mathrm{~Sv}$ as this deep northward flow is unaccounted for.

\section{Location of the measurements in the sub-arrays}

A schematic of the moorings that comprise the western boundary sub-array is shown in Fig. 2.2; the moorings that are merged to create the western boundary temperature and salinity profile are illustrated on the right, where each colour block represents a mooring that covers a particular time and depth range; the mooring names and zonal location of the moorings are shown on the left. The most important mooring is the WB2 mooring that extends from approximately $50 \mathrm{~m}$ below the surface to $3850 \mathrm{~m}$ depth, close to the steep continental shelf east of Abaco Island. The gradient of the continental slope is 0.35 near WB2, which is only $7 \mathrm{~km}$ offshore of the $1500 \mathrm{~m}$ isobath. This large gradient means that the continental slope acts similar to a vertical wall. Westward propagating mesoscale features cannot be sustained near to vertical walls and transform into meridionally propagating waves (Kanzow et al., 2009). The suppression of these westward propagating mesoscale features at the western boundary results in the RAPID array measuring a standard deviation of a few Sv (Cunningham et al., 2007) rather than $16 \mathrm{~Sv}$ that would be expected if an eddy dominated signal were being measured (Wunsch, 2008). In fact, the steepness of the western boundary proved to be a crucial element to the effective measurement of the basinwide AMOC signal in an eddy filled ocean. This, together with the Gulf Stream measurements in the Florida Strait, is why $26.5^{\circ} \mathrm{N}$ is such an excellent location to make these measurements.

One significant period of data interruption occurred on the western boundary. From November 2005 to March 2006, the WB2 mooring failed (Fig. 2.2). For this time period the mooring WB3 was the primary western boundary mooring. Repeating the calculation of the AMOC using WB3 as the western boundary generally leads to an increase in the rms variability of $1.9 \mathrm{~Sv}$ with a slight decrease in the mean strength of $0.3 \mathrm{~Sv}$ for these 5 months.

Fig. 2.3 shows the mooring schematic for the eastern boundary sub-array, showing the location of the moorings and the moorings chosen to construct the eastern boundary profile. In contrast to the western boundary, the eastern boundary has a gentle continental slope with an average gradient of 0.02 from $1000 \mathrm{~m}$ to $3000 \mathrm{~m}$ depth, dropping to 0.002 from $3000 \mathrm{~m}$ to $5000 \mathrm{~m}$ depth. The 


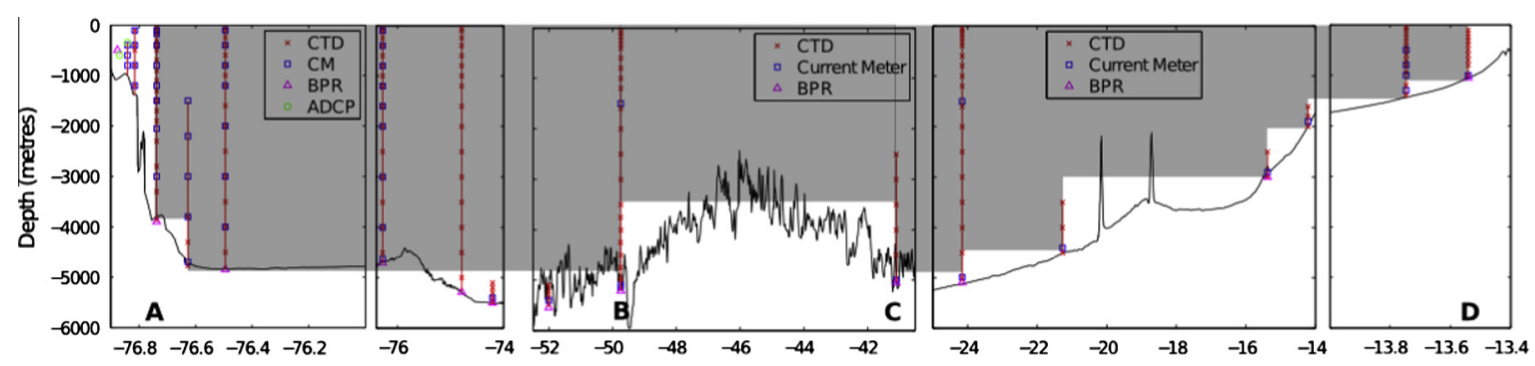

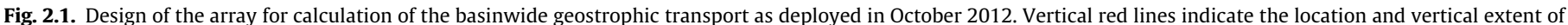

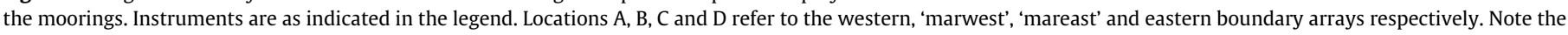

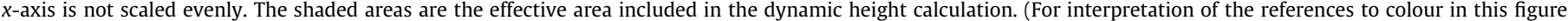
legend, the reader is referred to the web version of this article.)

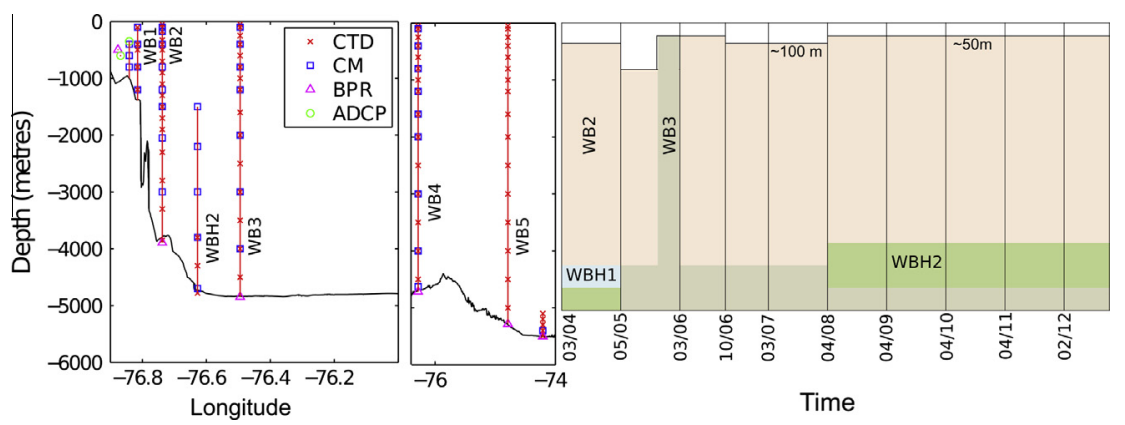

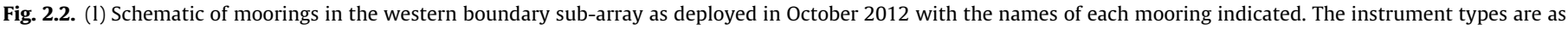

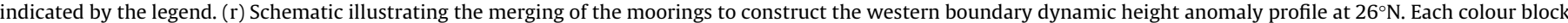

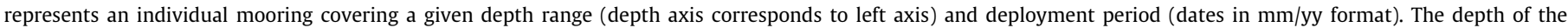

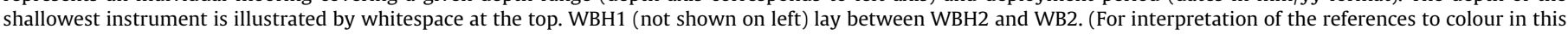
figure legend, the reader is referred to the web version of this article.)

eastern boundary array spans a much larger zonal extent with $1000 \mathrm{~km}$ separating the shallowest moorings on the $1000 \mathrm{~m}$ isobath from the deepest moorings on the $5000 \mathrm{~m}$ isobath. On average, 7 moorings are used to construct the eastern boundary profile in contrast to the 3 moorings used on the western boundary. This leads to regions known as bottom triangles below the deepest common measurement level between the moorings that are not sampled. The array is designed to minimise these bottom triangles. The full array covers $97 \%$ of the basin area-practically $100 \%$ shallower than $3000 \mathrm{~m}$. The impacts of bottom triangles are considered further in the conclusions.

Constructing the eastern boundary profile with moorings close to the continental shelf proved important for capturing the density fluctuations associated with the seasonal cycle of the AMOC (Chidichimo et al., 2010). From 2006 to 2008, a series of mini-moorings consisting of single CTDs and shallow-rated acoustic releases were deployed inshore of the $1000 \mathrm{~m}$ isobath to extend the merged density profile close to the African coast. The deployment of these mini-moorings ceased following heavy losses through what is thought to have been fishing activity: $58 \%$ of mini-mooring deployments were either not found or lost the CTD from the mooring. Since 2009, the top $1000 \mathrm{~m}$ of the water column is resolved by a mooring that sits on the $1000 \mathrm{~m}$ isobath (Fig. 2.3).

Another data loss at the eastern boundary occurred in February and March 2006 due to battery failure of eastern boundary instruments related to a firmware change. This gap was linearly interpolated over. Simulation of linear interpolation across any 2 month segment of data at the eastern boundary typically results in a decrease in the rms variability of the calculated 10-day filtered AMOC by $1 \mathrm{~Sv}$ with no significant impact on the mean.

Fig. 2.4 shows the schematic of the moorings at the mid-Atlantic ridge. These moorings are concentrated in two sub-arrays: one on the western flank of the ridge (marwest) and one at the eastern flank of the ridge (mareast). The mareast profile is constructed from a single mooring and hence the merging schematic is not shown. On the west flank, two moorings are merged to make a full depth profile (Fig. 2.4b).

The mareast mooring deployed in November 2009 was not recovered and a replacement was not deployed until January 2011. For this time period, mareast was replaced by average

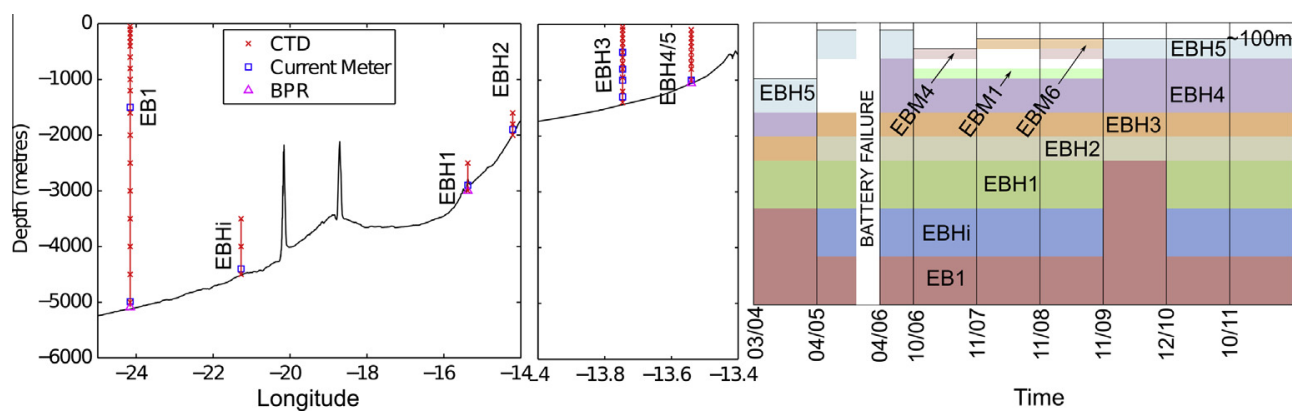

Fig. 2.3. Same as 2.1 but for Eastern boundary sub-array. Mini-moorings (EBM) were inshore of EBH $4 / 5$ at the depth corresponding to the right hand figure. 


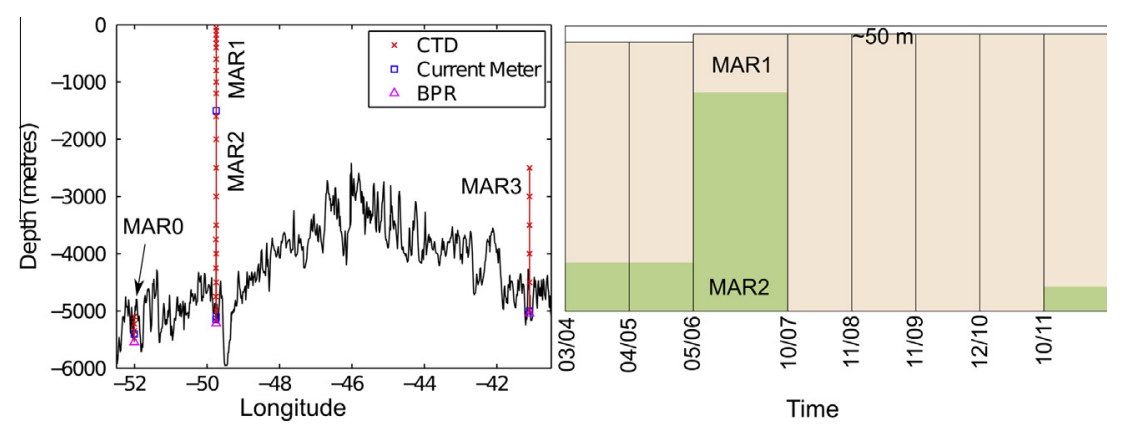

Fig. 2.4. Same as Fig. 2.1 but for mid-Atlantic ridge sub-array. Merging schematic for mareast is not shown as it is a single mooring (MAR3).

values. The estimated additional uncertainty and variance of the AMOC from this is not significant $(<0.1 \mathrm{~Sv})$ as the mareast mooring is more important to the mean structure of the deep circulation than to the variability of the full circulation as measurements shallower than 3800 dbar are unaffected.

\section{Calibration accuracy of moored CTDs}

As the calculation of the AMOC relies on geostrophic dynamics, the accurate determination of density from the moorings is crucial (Eq. (1.3)). Moored CTDs are used to measure temperature, salinity (via conductivity) and pressure on the moorings, from which density is calculated. In this section we describe the calibration procedure, the major sources of calibration inaccuracy and the size of that inaccuracy in terms of the impact on the AMOC calculation.

Pumped SeaBird CTDs are the instruments that are used on the moorings. These have a manufacturers specification for temperature (initial accuracy:stability:resolution) of $2 \mathrm{~m}^{\circ} \mathrm{C}: 0.02 \mathrm{~m}^{\circ} \mathrm{C} /$ month:0.01 m ${ }^{\circ} \mathrm{C}$; for conductivity of $0.003 \mathrm{mS} / \mathrm{cm}: 0.003 \mathrm{mS} / \mathrm{cm} /$ month: $0.0001 \mathrm{mS} / \mathrm{cm}$; and for pressure of $0.1 \%$ full-scale: $0.05 \%$ of full scale range per year:0.002\% of full scale range (Sea-Bird Electronics, 2014). All moored instruments are calibrated against shipboard CTDs prior to and following deployment as described in Kanzow et al. (2006), rather than being calibrated in a laboratory. Temperature and conductivity calibration coefficients are calculated by examining the average difference between the shipboard and moored CTD data after the instruments have had a chance to equilibrate $(>5 \mathrm{~min})$ at deep $(>2000 \mathrm{~m}$ ) bottle stops. Pressure coefficients are determined using the difference between the deployment depths of the moored instrument and the shipboard CTD. A least squares polynomial extrapolation is performed to derive the pressure coefficient if the shipboard CTD cast was shallower than the depth at which the moored CTD was deployed. Pre and post calibration coefficients are then used to calibrate the moored CTD data with either a constant offset or a linear trend. Any pressure drifts and spurious data are removed if necessary. A detailed analysis of this method by Rayner et al. (in preparation) shows that this method of shipboard calibration of temperature and salinity compares well with laboratory calibration of moored CTDs. They also show that the adjustments required for the instruments are frequently less than the manufacturer's stated accuracy and stability. Following this calibration procedure, we estimate that the accuracy of the moored instruments is approximately $1 \mathrm{dbar}: 0.002{ }^{\circ} \mathrm{C}: 0.003$ for pressure:temperature:salinity respectively over the duration of the deployment.

Calibration inaccuracies can affect the calculation of the AMOC in two ways: errors due to individual instruments being inaccurate or systematic biases between density profiles on the eastern or western boundary (Eq. (1.4)). We expect no systematic bias in the accuracies of the instruments themselves. Hence random errors due to individual instruments in each boundary dynamic height anomaly profile are offset by the fact that, on average, there are 20 instruments in each profile. This reduces the standard error in each profile due to potential inaccuracies of individual instruments substantially. On the other hand, from 2004 to 2012, the eastern and western sub-arrays were serviced on different cruises i.e. the instruments were calibrated against different CTDs. Temperature measured by shipboard CTDs is highly accurate and stable, and is not generally adjusted by calibration. Salinity measured by shipboard CTDs, on the other hand, does need to be calibrated against standard seawater. Pressure measured by shipboard CTDs is not adjusted. In comparison with shipboard CTDs, moored CTD temperature is accurate and often not adjusted whereas moored CTD salinity and pressure does need to be calibrated against shipboard CTDs. Hence the limiting factor is the accuracy of the salinity and pressure of the CTD against which the instruments are calibrated.

Salinity proves to be the most important factor is terms of impact on the AMOC calculation. A 0.003 difference in salinity between eastern and western profiles leads to a $0.7 \mathrm{~Sv}$ error in the estimated AMOC. In comparison, a 1 dbar bias in pressure results in a $0.05 \mathrm{~Sv}$ error in the estimated AMOC. Pressure errors also affect the calculation of salinity. A 1 dbar error in pressure leads to a 0.0005 error in salinity. We do not consider a temperature bias as temperature measurements are very consistent but, for comparison, a $0.002{ }^{\circ} \mathrm{C}$ error in temperature leads to a $0.1 \mathrm{~Sv}$ error in the estimated AMOC. Temperature has a large effect on the calculation of salinity with a $0.001^{\circ} \mathrm{C}$ error in temperature causing a 0.001 error in salinity. Hence, the compound effect of a $0.002{ }^{\circ} \mathrm{C}$ error in temperature would be a $0.6 \mathrm{~Sv}$ error in the calculated AMOC. In summary, salinity and pressure are vulnerable to bias due to their necessary calibration against shipboard CTDs. A salinity bias of 0.003 and a pressure bias of $1 \mathrm{dbar}$ (including the pressure effect on salinity) would lead to an error in the estimated AMOC of $0.9 \mathrm{~Sv}$.

This 0.9 Sv error results from consideration of the measurement inaccuracy at one boundary. The maximum error is double this value as an opposite error could occur on the opposite boundary. To compare with other rms errors quoted in this text, we consider the $1.8 \mathrm{~Sv}$ maximum error to be equivalent to the $95 \%$ value. Scaling this value by dividing by a 1.64 (i.e. assuming the errors to be normal), and converting it by considering the 2 shipboard CTDs as the sample number, we get an estimated error of $0.8 \mathrm{~Sv}$ in the AMOC calculation due to the calibration error.

The major source of error arising from potential biases due to the intercalibration of the sub-arrays means that longer term averaging does not significantly increase the accuracy of the calculation. Consider a year segment: typically the eastern boundary array was deployed autumn to autumn and the western boundary array from spring to spring. For a given year, there are three independent calibrations of each sub-array. If the major error is the difference between two independent calibrations, then an annual average only increases the number of samples from 2 to 3 . Hence the error estimate of $0.8 \mathrm{~Sv}$ only reduces to $0.6 \mathrm{~Sv}$ on annual 
averaging. The issue of intercalibration of CTDs has been removed following McCarthy (2012) when the full array was refurbished in a single cruise. This allows all instruments to be calibrated against a single CTD, reducing possible calibration bias between east and west salinities.

\section{Merging and gridding}

The calculation of the dynamic height anomaly profiles requires the interpolation of the relatively sparse moored instrument data onto a high resolution vertical grid. This is achieved by integrating climatology-derived temperature and salinity gradients between adjacent instruments to produce temperature and salinity on a 20 dbar grid (Johns et al., 2005; Kanzow et al., 2006).

The Hydrobase climatology (Curry and Nobre, 2008) is used to derive monthly values of $\partial T / \partial p$ and $\partial S / \partial p$ that specify the mean vertical temperature and salinity gradients as a function of temperature at the locations of the moorings. Fig. 2.5 shows the monthly climatological gradients for the western and eastern boundaries. A seasonal cycle is present in the surface waters above $300 \mathrm{dbar}$, approximately $18^{\circ} \mathrm{C}$. Piecewise second order polynomials are fitted to temperature and salinity profiles from the climatology to compute smooth first and second order vertical derivatives. These were then mapped onto temperature levels as Johns et al. (2005) found temperature a more stable variable than depth for gridding.

Temperature and salinity on the 20 dbar grid are calculated using the method of Johns et al. (2005). For temperature, the climatological $\partial T / \partial p$ is combined with the actual temperatures by integrating upwards and downward from adjacent measurement points on the mooring and forming a weighted average of these estimates (Johns et al., 2005):

$T(p)=\sum_{i=1}^{2} w_{i}\left[T\left(p_{i}\right)+\int_{p_{i}}^{p} \frac{\partial T}{\partial p}(T) d p\right]$,

where

$w_{i}=1-\frac{\left|p-p_{i}\right|}{p_{2}-p_{1}}$,

and $i=1,2$ are adjacent measurement levels, and the weights $w_{i}$ are inversely proportional to the vertical distance from the measurement depths. The same procedure is used to produce a $20 \mathrm{dbar}$ salinity field. This procedure forces the temperature and salinity profiles through the measured points of the mooring while being consistent with the local seasonal stratification.

The transport errors associated with this method of gridding are assessed by subsampling high resolution CTD profiles at typical moored instrument vertical separation. Moored instruments are placed closer together in regions of larger vertical gradients. A guideline is that instruments shallower than 500 dbar have separations less than $100 \mathrm{dbar}$, instruments between $500 \mathrm{dbar}$ and 2000 dbar have separations around 200 dbar and instruments deeper than 2000 dbar have separations of approximately $500 \mathrm{dbar}$. Subsampling temperature and salinity from the CTD profiles at these intervals, we construct simulated 'moored' high resolution dynamic height anomaly profiles around the eastern and western boundaries by using Eq. (2.1) and, for comparison, by linear interpolation. The AMOC is estimated using both of these reconstructed profiles and compared to the value computed using the full CTD profiles. Using Eq. (2.1) results in an rms error of $0.4 \mathrm{~Sv}$ and a small bias of $0.04 \mathrm{~Sv}$. By comparison, linear interpolation results in an rms error of $0.5 \mathrm{~Sv}$ and a much larger bias of $0.3 \mathrm{~Sv}$, underestimating the AMOC. The bias arises from linear interpolation across rapidly changing gradients in the top $1000 \mathrm{~m}$. While this gridding procedure does not reduce the rms error in the profiles by a large amount, the virtual elimination of a bias is a marked improvement.
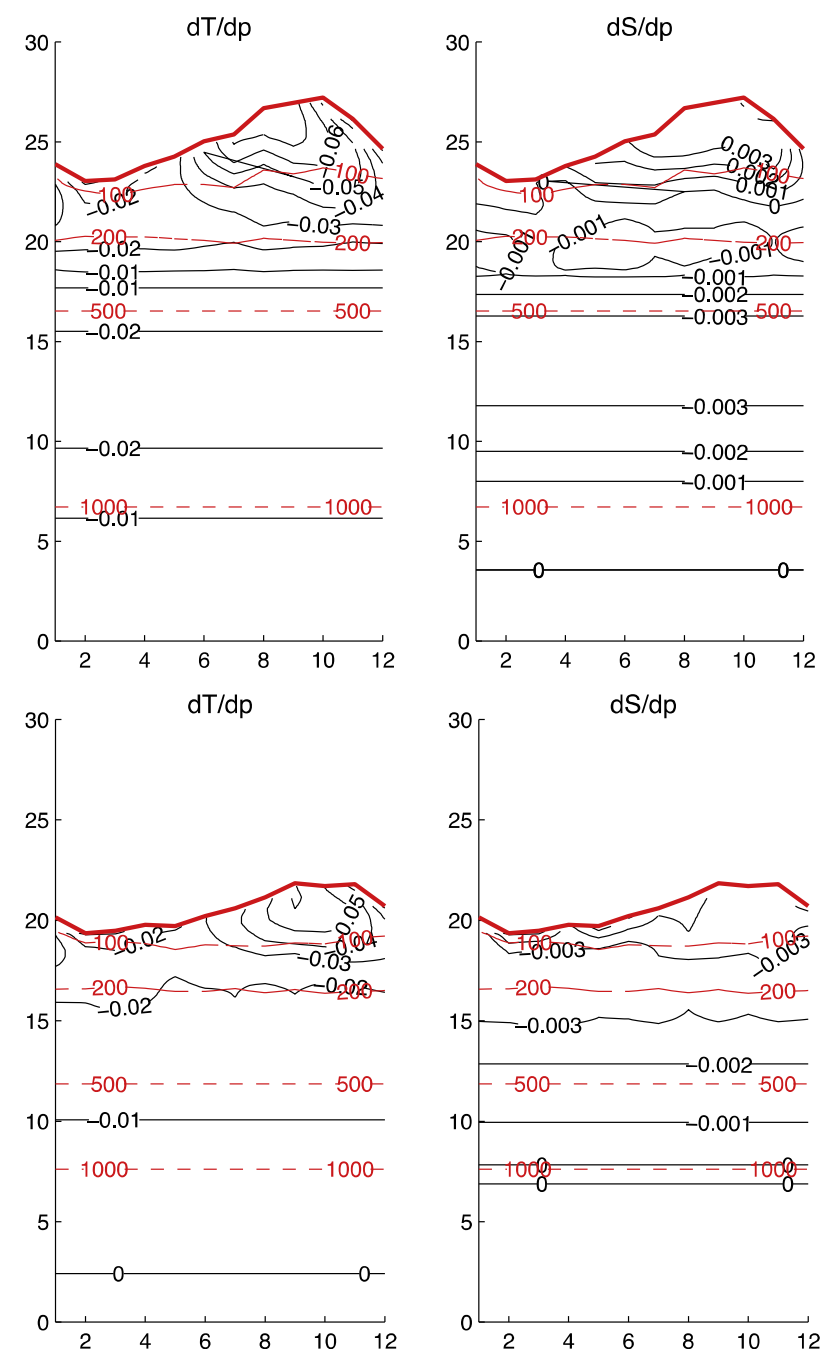

Fig. 2.5. Values of monthly of $\partial T / \partial p$ and $\partial S / \partial p$ (black contours) against temperature at (top) the western and (bottom) eastern boundaries. The marwest climatology is similar to the western climatology. Pressures are shown with red contours with heavy red line indicating the 50 dbar mark. (For interpretation of the references to colour in this figure legend, the reader is referred to the web version of this article.)

The size of the error associated with gridding in a general framework is considered by examining the error associated with the rate of change of the vertical gradient in temperature and salinity. The right hand side of Eq. (2.1) is recognisable as the first two terms of a weighted Taylor expansion. Therefore, the next term of the expansion can be considered as an estimate of the next largest error term. For example, the temperature error associated with the next largest term in the expansion may be expressed as:

$T_{\text {error }} \sim \frac{1}{2} \frac{\partial^{2} T}{\partial p^{2}}\left(p-p_{i}\right)^{2}$

where $p_{i}$ is the pressure of the nearest instrument. This allows us to estimate the errors associated with the gridding technique. Fig. 2.6 shows this error term contoured against instrument separation and rates of shear change. Based on the typical separation of instruments described in the previous paragraph, the maximum distance from an instrument and typical rates of shear change are highlighted with red crosses. Maximum errors in temperature (salinity) are of the order of $0.05{ }^{\circ} \mathrm{C}(0.01)$ shallower than $2000 \mathrm{dbar}$. Below $2000 \mathrm{dbar}$, the shear change is small and errors due to gridding drop below instrumental accuracy. 
The impact of utilising a monthly rather than an annual gridding climatology is quite small. Annual climatologies do not contain a seasonal cycle and may underestimate the shear in the upper ocean. Using a seasonal gridding climatology rather than an annual leads to the estimated AMOC being stronger by $0.05 \mathrm{~Sv}$ in September and weaker by $0.01 \mathrm{~Sv}$ in February.

While the vertical gradients on the east are more forgiving in terms of gridding, there have been more instrument losses. Here we investigate the errors arising from these losses by simulating missing instruments in CTD data. The losses at the eastern boundary, primarily due to the mini-mooring losses, are illustrated in Fig. 2.3. From 2006 to 2008, there was no instrument at 300 dbar; simulating the absence of this instrument indicates no discernable bias but a small increase in rms error of $0.2 \mathrm{~Sv}$. However, during 2007, there was no instrument at $200 \mathrm{dbar}$ or $300 \mathrm{dbar}$. Simulating these missing instruments indicates a transport bias of $0.4 \mathrm{~Sv}$ and increases the rms error by $0.9 \mathrm{~Sv}$ due to larger gridding errors for 2007. In 2004, data were not present shallower than 540 dbar. These data were gridded by linearly extrapolation from $840 \mathrm{dbar}$ to $540 \mathrm{dbar}$ and held constant thereafter. Simulation of this method results in no bias arising but an increase of rms error of $0.5 \mathrm{~Sv}$.

In summary, the use of seasonal climatological gradients to increase the vertical resolution of the moored profiles are effective
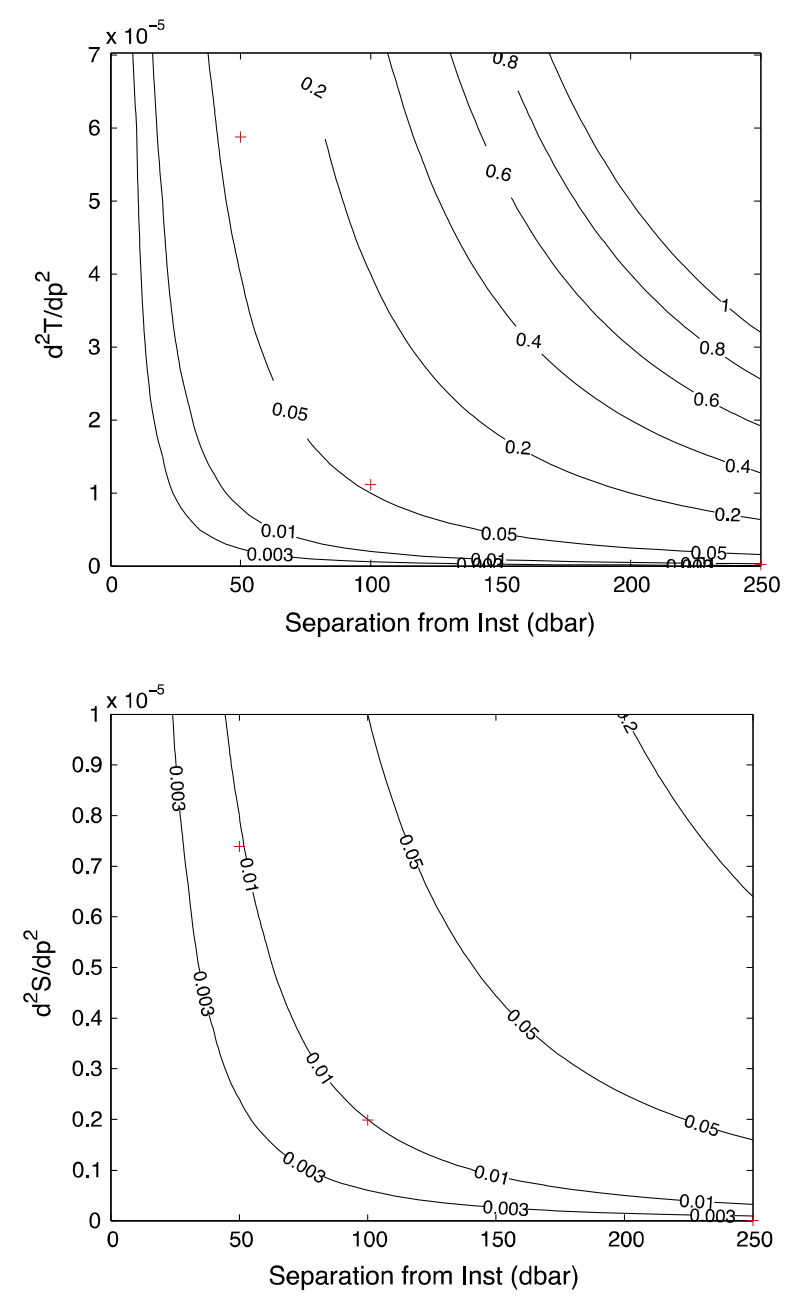

Fig. 2.6. Estimates of next order gridding error based on Eq. (2.2) for temperature $\left({ }^{\circ} \mathrm{C}\right.$, top) and salinity (bottom) gridding errors. Red crosses indicate errors for the typical maximum distance from an instrument and associated rates of shear change for a RAPID mooring. (For interpretation of the references to colour in this figure legend, the reader is referred to the web version of this article.) at improving the accuracy of the dynamic height anomaly profiles. The rms uncertainty in the estimated AMOC due to gridding is $0.4 \mathrm{~Sv}$ for the whole timeseries. The loss of instruments increases the errors by $0.2 \mathrm{~Sv}, 0.9 \mathrm{~Sv}$ and $0.2 \mathrm{~Sv}$ for 2006, 2007 and 2008 with a bias of -0.4 Sv for 2007 .

The shallowest transports: the transport above the shallowest instrument

RAPID moorings are designed to have the shallowest measurement at $50 \mathrm{~m}$ to avoid the high loss rates associated with surface expressions of moorings (McPhaden et al., 2010). In reality, a depth of $50 \mathrm{~m}$ for the shallowest measurement is difficult to achieve since moorings tend to be knocked down in the presence of strong currents.

Table 2.1 shows the percentages of profiles with the shallowest measurement in a given depth range. Most of the profiles have the shallowest measurement in the 100-200 dbar depth range-deeper than the depth of the shallow summer thermocline that begins around 50 dbar. To calculate transport above the shallowest measurement, a seasonally varying extrapolation technique is required. Here we compare linear extrapolation of geostrophic shear with methods that account for the seasonally changing rates of shear in the shallowest layers.

Fig. 2.7 illustrates the problem of surface extrapolation at the western boundary using monthly data from an Argo based climatology (Roemmich and Gilson, 2009). When data are not present shallower than $200 \mathrm{dbar}$, linear extrapolation does not capture changing rates of shear shallower than $150 \mathrm{dbar}$. This leads to transports of between $1 \mathrm{~Sv}$ in February and $2 \mathrm{~Sv}$ in August not being captured by linear extrapolation. Terms of higher order than linear in depth are necessary (Fig. 2.7):

Cubic terms are needed to adequately resolve the changes in geostrophic shear in the shallowest layers. A model of the form:

$$
\begin{aligned}
\Phi\left(z_{e}\right)= & \Phi_{k-1}+\frac{z_{e}-z_{k-1}}{z_{k}-z_{k-1}}\left(\Phi_{k}-\Phi_{k-1}\right)+\alpha_{i}\left(z_{e}-z_{r}\right)^{2}+\beta_{i}\left(z_{e}-z_{r}\right)^{3} \\
& -\Phi_{\text {step }}\left(z_{k}\right)
\end{aligned}
$$

is used for accurate extrapolation, where $\Phi$ is dynamic height anomaly, $z_{e}$ is extrapolation depth, $z_{k}$ indicates the depth of the shallowest measurement. The parameters $\alpha$ and $\beta$ are discrete variables dependent on month $i$, calculated relative to reference depth $z_{r}$-here chosen to be $200 \mathrm{dbar}$. The first two terms on the right hand side of the equation describe linear extrapolation above the shallowest measurement, the second two terms describe the monthly varying quadratic and cubic extrapolation above the reference depth, and the final term ensures continuity at the depth of the shallowest measurement.

To calculate the parameters $\alpha$ and $\beta$, reference datasets close to the key locations of the moorings were assembled from a combination of Argo profiles, World Ocean Database (WOD) profiles and glider profiles (Smeed and Wright, 2009). Fig. 2.8 shows the locations of these profiles at the eastern and western boundaries. The Argo and glider data are particularly useful for providing seasonally unbiased data while the targeted WOD data provide important measurements near to the continental shelf of the Bahamas. The glider data provides measurements around the $1000 \mathrm{~m}$ isobath

Table 2.1

Percentage of profiles at the western and eastern boundary with the shallowest instrument in the indicated depth range.

\begin{tabular}{llll}
\hline & $\leqslant 100 \mathrm{dbar}$ & $200-100 \mathrm{dbar}$ & $\geqslant 200 \mathrm{dbar}$ \\
\hline Western boundary (\%) & 39 & 49 & 10 \\
Eastern boundary (\%) & 14 & 84 & 1 \\
\hline
\end{tabular}




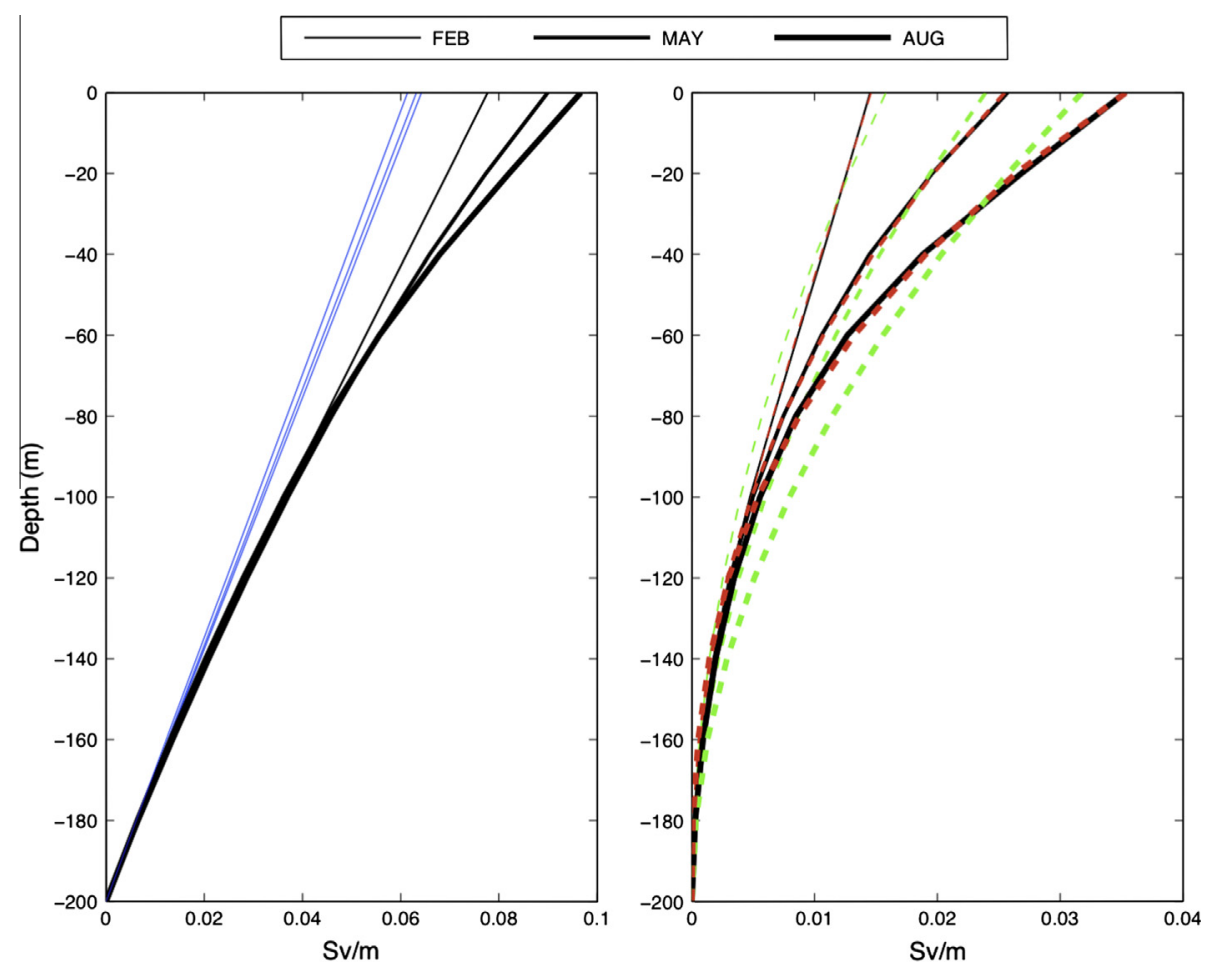

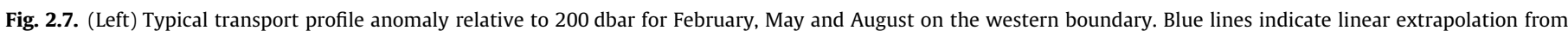

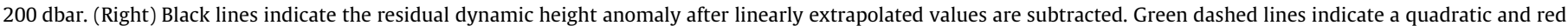
lines indicate a cubic fit to the black lines. (For interpretation of the references to colour in this figure legend, the reader is referred to the web version of this article.)

where the key eastern mooring is located. The parameters $\alpha$ and $\beta$ were then calculated by multiple linear regression against dynamic height anomaly profiles from each month.

The results were tested robustly by randomly selecting half of the profiles to calculate the parameters and using the other half of the profiles to calculate the resulting transport error due to the method of extrapolation. This was performed on the eastern and western boundaries by simulating extrapolation above 200 dbar (Fig. 2.9) and above 100 dbar (Fig. 2.10). Errors due to linear extrapolation are largest at the western boundary. On average, $2 \mathrm{~Sv}$ of transport is missed by linear extrapolation above $200 \mathrm{dbar}$ with an annual range of $\pm 0.5 \mathrm{~Sv}$. The new method of extrapolation reduces this to below $0.5 \mathrm{~Sv}$ with little annual range. On the eastern boundary, $0.5 \mathrm{~Sv}$ of transport is missed due to linear extrapolation. The new method reduces this to practically zero. Linear extrapolation above $100 \mathrm{dbar}$ at the western boundary misses $0.2 \mathrm{~Sv}$ in February, rising to $1 \mathrm{~Sv}$ in August, with the new method reducing this below $0.2 \mathrm{~Sv}$. On the eastern boundary, linear extrapolation above $100 \mathrm{dbar}$ misses $0.2 \mathrm{~Sv}$ with the new method reducing this to practically zero also. The implications are that, when the shallowest measurement is at $200 \mathrm{dbar}$, linear extrapolation results in an extra $1.5 \mathrm{~Sv}$ of northward basinwide flow and, when the shallowest measurement is at $100 \mathrm{dbar}$, linear extrapolation results in an extra $0.7 \mathrm{~Sv}$ in August and $0.2 \mathrm{~Sv}$ in February.

The seasonal behaviour at the western boundary is also typical of that at the mid-Atlantic ridge i.e. strong seasonality in the upper 50 m due to the development of a shallow, warm seasonal thermocline in the late summer. In this respect, the eastern boundary is
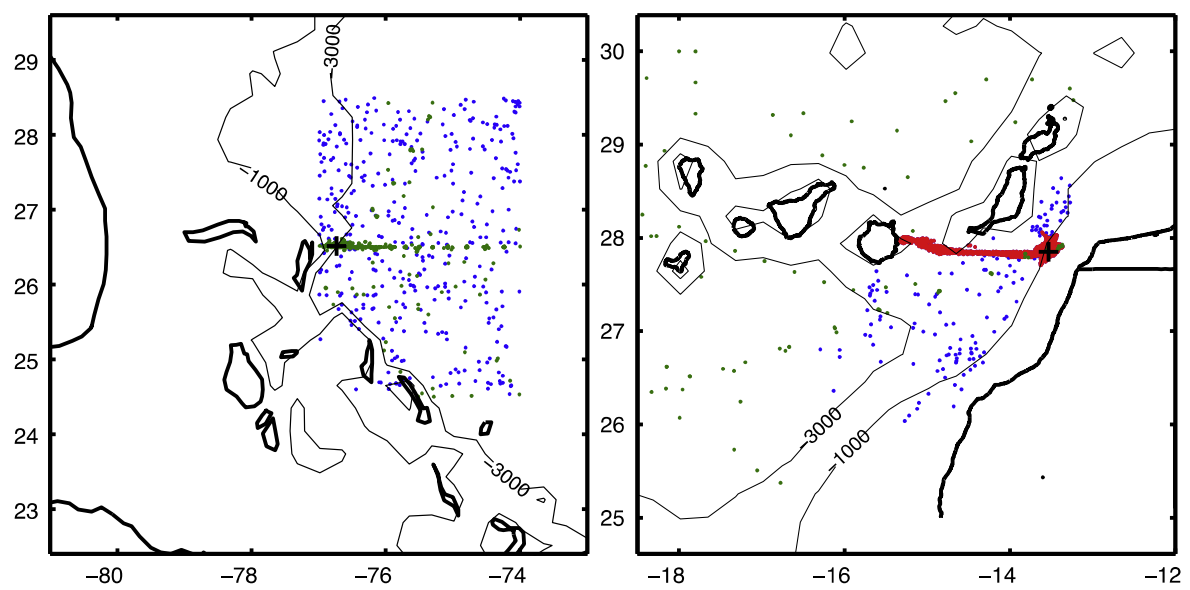

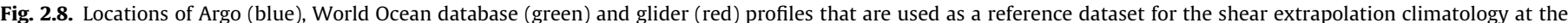

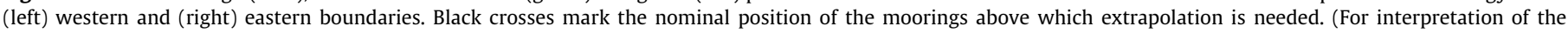
references to colour in this figure legend, the reader is referred to the web version of this article.) 

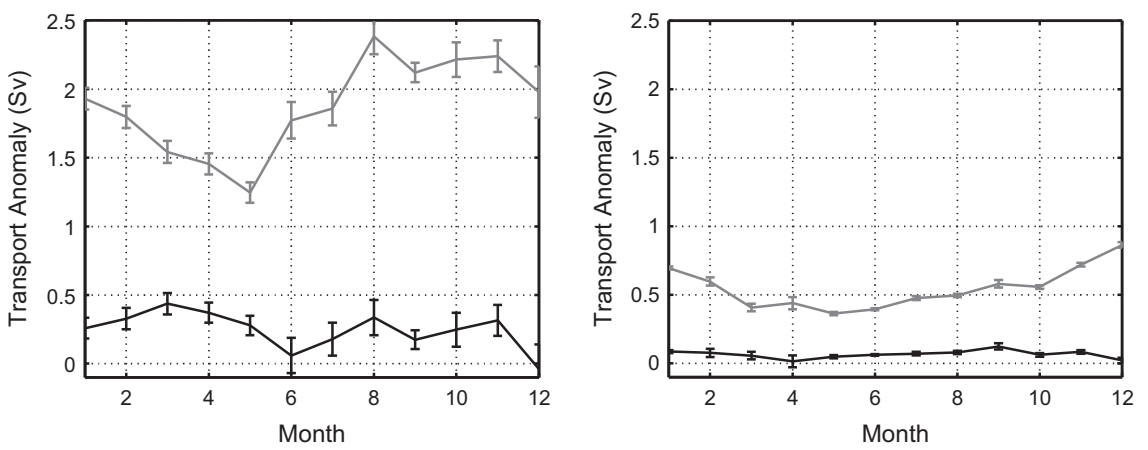

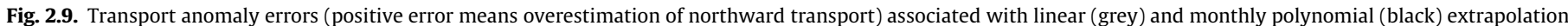
above 200 dbar for (left) western and (right) eastern boundaries. Error bars are \pm 1 standard error.
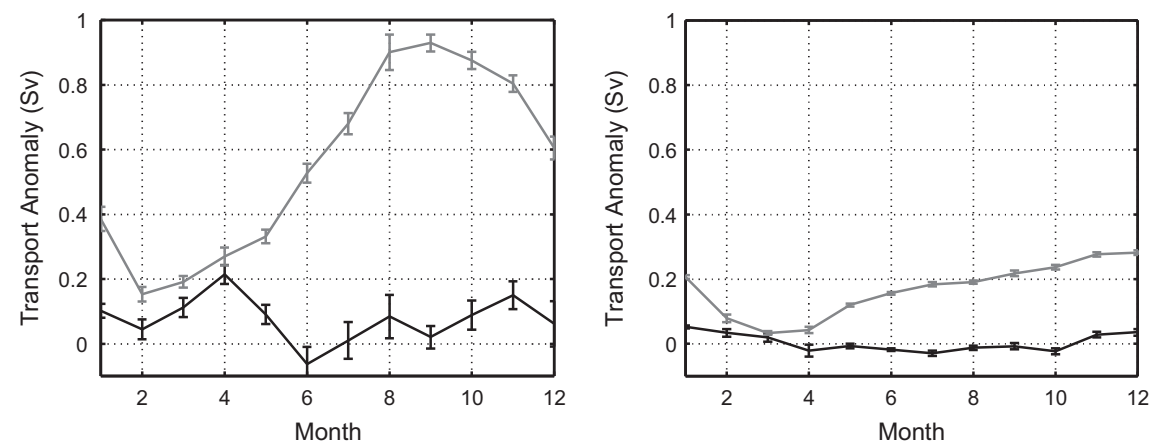

Fig. 2.10. As Fig. 2.9 but for extrapolation above $100 \mathrm{dbar}$.

different from the rest of the basin being in an upwelling regime where the seasonal effects of heating are negated by the strong upwelling that occurs during the late summer and autumn e.g. Mittelstaedt (1983).

Alternative methods for extrapolation were also considered. Using a sea surface temperature (SST) value (Reynolds et al., 2007) with a climatological sea surface salinity point and interpolating to the shallowest measurement using the methods described in Section 'Merging and gridding' was tested. This proved effective when the shallowest measurement was at $100 \mathrm{dbar}$ but had errors of $\pm 0.5 \mathrm{~Sv}$ when the shallowest measurement was at $200 \mathrm{dbar}$. Seasonal errors also remained using this method as SST and dynamic height anomaly integrated through the seasonal mixed layer lag one another due to the persistence of cold temperatures in the deep winter mixed layer. Incorporation of a measured SST value would allow for interannual variability. However, no discernable interannual variability was found in the parameters $\alpha$ and $\beta$ so its inclusion did not improve the results.

As noted above, previous versions of the RAPID calculation have used linear extrapolation of dynamic height anomaly above the shallowest measurement and will contain errors of the magnitude described here. Haines et al. (2013) compared the RAPID measurements with two data assimilating models and found that the models had an additional $1.5 \mathrm{~Sv}$ flowing southwards in the top $150 \mathrm{~m}$ during late summer, leading to a reduction of $1.1 \mathrm{~Sv}$ in the strength of the AMOC. Their conclusion that this was likely to be the result of the extrapolation method used in previous RAPID calculations is consistent with the conclusions here. The method of seasonal extrapolation presented here significantly improves the transport estimates in the upper few hundred metres.

In summary, this new method reduces the mean strength of the estimated AMOC by $0.4 \mathrm{~Sv}$ over the full duration of the timeseriesthis is due to little change in the winter months and around a $1 \mathrm{~Sv}$ decrease in the estimated AMOC during late summer. The change acts to slightly decrease the amplitude of the seasonal cycle as described by Kanzow et al. (2010).

\section{The deepest measurements: estimates of Antarctic Bottom Water transport}

The deepest measurements pose challenges due to the large pressures and often highly variable topography in the abyssal ocean. The RAPID array measures from the near surface to 4820 dbar. However, most of the northward flowing Antarctic Bottom Water (AABW) occurs deeper than this. Between 2.2 and 3.7 Sv of AABW flows northwards in waters colder than $1.8^{\circ} \mathrm{C}$ at $26^{\circ} \mathrm{N}$ in the region of $70.5^{\circ} \mathrm{W}$ and $49^{\circ} \mathrm{W}$ (Frajka-Williams et al., 2011). Here we incorporate two years of deep moored measurements into the estimation of the AMOC to assess the mean structure and variability of the flow deeper than 4820 dbar.

Two years of continuous mooring data measuring the deep flow are available from April 2009 to April 2011. The key deep moorings are WB6 and MAR0 (Fig. 2.11). These are combined with WB5 and MAR1 respectively to create merged temperature and salinity profiles that extend to $5500 \mathrm{~m}$. These profiles are appended to the full western boundary profile and to the marwest profile. The extended western and marwest profiles can then be included in the full basinwide transport calculation as described in Section 'Design of the array'. Dynamic height anomaly is calculated from the extended western boundary and the marwest profiles and differenced to calculate the geostrophic flow between them. Following the methods established by Frajka-Williams et al. (2011), these dynamic height anomaly profiles are referenced to $4100 \mathrm{dbar}$ and linearly interpolated from $5500 \mathrm{dbar}$ to zero at $6000 \mathrm{dbar}$, the area of the section deeper than 6000 dbar being quite small. 


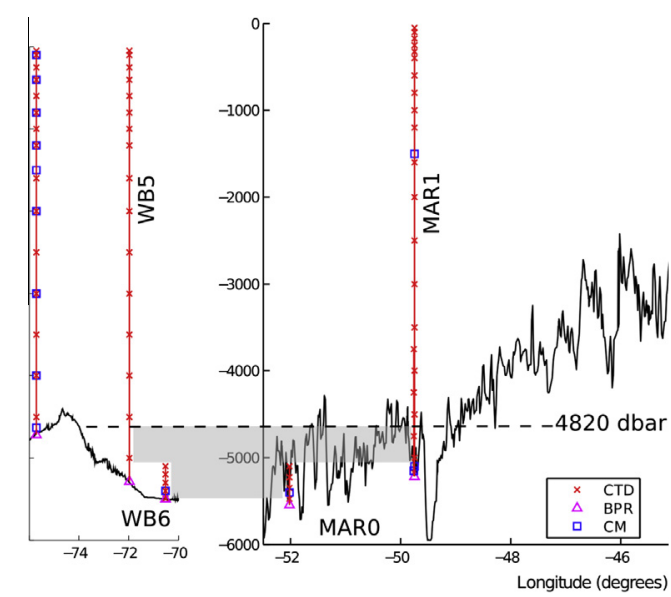

Fig. 2.11. Location of the moorings that are used for calculating northward flow below $4820 \mathrm{dbar}$, which includes AABW. Grey shading indicates the area that the flow is calculated.
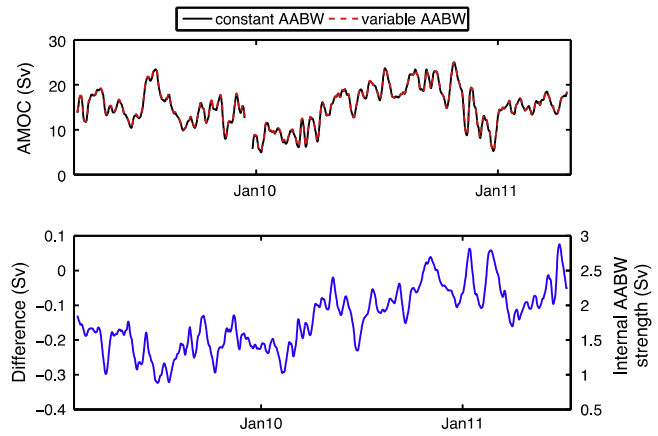

Fig. 2.12. (Top) Full AMOC strength calculated with a constant $A A B W$ profile equivalent to $2 \mathrm{~Sv}$ (black) and with a variable AABW (red, dashed). (Bottom) Difference in AMOC strength between the two methods. This scales linearly with the internal geostrophic AABW flow (right hand axis). (For interpretation of the references to colour in this figure legend, the reader is referred to the web version of this article.)

Fig. 2.12 shows the AMOC transport calculated with mooring derived AABW estimates and using a time-invariant profile of AABW transport. Incorporation of the deep moorings results in a small mean increase of $0.1 \mathrm{~Sv}$ in the estimation of the AMOC. The difference between the two calculations scales linearly with the internal geostrophic transport between the deep section of the dynamic height anomaly profiles. This deep transport ranges from $1 \mathrm{~Sv}$ to $3 \mathrm{~Sv}$ in 2009 and 2010. The ratio between the change in the calculated AMOC and internal deep transport is $1: 5$ so that a $1 \mathrm{~Sv}$ increase in geostrophic flow deeper than 4820 dbar reduces the AMOC by $0.2 \mathrm{~Sv}$. Therefore the impact of time varying AABW transports on the variability in the calculated AMOC transport is $\pm 0.2 \mathrm{~Sv}$.

The mean transport at pressures greater than 4820 dbar is shown in Fig. 2.13. The transport has a mean of approximately $1 \mathrm{~Sv}$. This is half the transport of AABW reported by FrajkaWilliams et al. (2011). Much of this discrepancy is due to the fact that here we estimate transport deeper than $4820 \mathrm{dbar}$, which includes some southward flow west of $72^{\circ} \mathrm{W}$. Traditional definitions of $A A B W$ isolate the northward flowing water mass and hence result in more northward flow of AABW.

The mean vertical structure of the deep flow from the moored observations is compared with the time-invariant profile used in previous RAPID calculations in Fig. 2.14. The time-invariant profile was based on a number of hydrographic sections in Kanzow et al.
(2010). It is likely that the sparse temporal sampling of the hydrographic sections and variations in the depth of the hydrographic profiles lead to a less smooth profile than that derived from the moorings. A new time-invariant profile based on the moored measurements below 4820 dbar is now used for the calculation of the full RAPID timeseries. This has a mean value of $1 \mathrm{~Sv}$ and a vertical structure as indicated in Fig. 2.14. Use of this profile reduces the estimated AMOC by $0.2 \mathrm{~Sv}$ relative to previous calculations.

\section{Equation of state: TEOS-10}

The Thermodynamic Equation of State for seawater was introduced in 2010, here referred to as TEOS-10, replacing the previous equation of state, EOS-80. The new equation of state has a nonnegligible impact on densities and hence on the calculation of geostrophic transport of the AMOC. Here, we calculate the AMOC using the new equation of state and contrast with the previous calculation.

TEOS-10 provides a thermodynamically consistent definition of the equation of state in terms of the Gibbs function for seawater. It introduces conservative temperature, defined to be proportional to enthalpy, as a more accurate measure of the heat content of seawater. Perhaps the most notable change is the use of absolute salinity. Absolute salinity, or density salinity, is the salinity that most accurately reflects the density of a seawater sample in the TEOS-10 equation of state. Calculation of absolute salinity from practical salinity is a two stage process. First, reference salinity is calculated as the best estimate of the absolute salinity of standard seawater (Millero et al., 2008)-this is practical salinity multiplied by a constant factor of $35.165 / 35$. Secondly, a geographically varying factor is added to reflect the impact on seawater density of the variation of the composition of seawater in different ocean basins, notably the impact of silicate (IOC et al., 2010). It is this geographically varying factor that results in the largest change in the geostrophic transports calculated at $26^{\circ} \mathrm{N}$.

Fig. 2.15a shows the difference between geostrophic transport streamfunctions (Eq. (1.5)) calculated from EOS-80 and TEOS-10 based on moored hydrographic profiles on either side of the basin at $26.5^{\circ} \mathrm{N}$. Excluding the geographically varying factor from absolute salinity and using the new equation of state results in little change in the transport streamfunction. When this geographically varying factor is included, the use of TEOS-10 results in a weaker streamfunction at all depths. A maximum difference of $0.7 \mathrm{~Sv}$ occurs around 2700 dbar. At the depth of the AMOC, $1100 \mathrm{dbar}$, the difference is $0.4 \mathrm{~Sv}$. This is the reduction in the strength of the AMOC due to the change in the equation of state.

To analyse the changes, we look at the impact on specific volume anomaly due to the new equation of state. Fig. 2.15b shows changes in specific volume anomaly calculated using values derived from the TEOS-10 toolbox relative to values derived from EOS-80 both including and not including the geographically varying factor in absolute salinity. In the top $2000 \mathrm{~m}$, changes are evident due to the new formulation of the equation of state and are present whether or not the geographically varying factor is included. At pressures greater than $1500 \mathrm{dbar}$, there is little change due to the new formulation of the equation of state and the changes are dominated by the geographically varying factor included in absolute salinity.

The geographical variation in absolute salinity can be understood in terms of the distribution of silicate at $26^{\circ} \mathrm{N}$. Silicate is the single largest contribution to the geographical variation of absolute salinity. Higher concentrations of silicate on the eastern boundary have an impact on the density and therefore the geostrophic circulation.

The use of TEOS-10 rather than EOS- 80 has reduced the AMOC estimate by $0.4 \mathrm{~Sv}$ or approximately $2 \%$, primarily due to the 


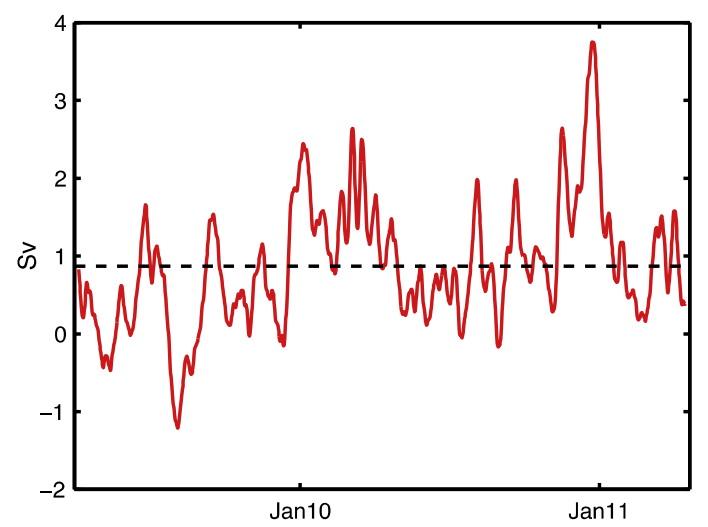

Fig. 2.13. The transports deeper than 4820 dbar during the period of time-varying AABW with the mean highlighted by the black, dashed line.

consideration of higher silicate concentrations at the eastern boundary in the calculation of density. This is in line with the magnitude of expected changes described in IOC et al. (2010).

\section{Additional components in the AMOC calculation}

\section{The Gulf Stream in the Florida Straits}

The Gulf Stream is confined to the shallow $(<800 \mathrm{~m})$, narrow Florida Straits near the latitude of $26^{\circ} \mathrm{N}$. The confinement of the primary western boundary upper-ocean current geographically makes $26^{\circ} \mathrm{N}$ an ideal location for measurement and separation of the components of ocean circulation there. The transport of the Gulf Stream has been measured nearly continuously by a submarine cable at about $27^{\circ} \mathrm{N}$ since 1982 (Baringer and Larsen, 2001; Meinen et al., 2010), with routine hydrographic sections being collected for cable calibration multiple times per year, making it one of the longest running and most valuable timeseries in oceanography. The existence of this timeseries made $26^{\circ} \mathrm{N}$ the natural location for a basin-wide array monitoring the full AMOC.

The Gulf Stream has a mean strength of $32 \mathrm{~Sv}$, with a daily standard deviation of about $3 \mathrm{~Sv}$ and a small seasonal cycle with a peakto-peak amplitude less than $3 \mathrm{~Sv}$. It is estimated that the daily transport measurements are accurate to within $1.1 \mathrm{~Sv}$ and annual averages are accurate to within $0.3 \mathrm{~Sv}$ over the time period of the RAPID measurements (Meinen et al., 2010; Garcia and Meinen,

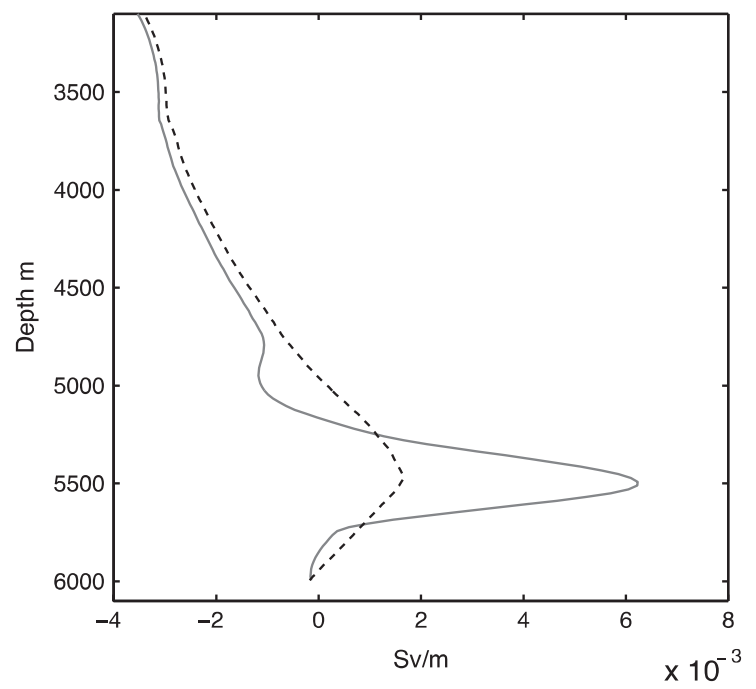

Fig. 2.14. New (black, dashed) profile of northward flow of below 4820 dbar and old (grey, solid) profile derived from hydrographic sections.
2014). The Gulf Stream in the Florida Straits has had a remarkably constant strength with no statistically significant long term trends discernable relative to the energetic shorter term variability.

A short gap of 56 days from 3/9/2004 to 29/10/2004 exists during the RAPID time period after a hurricane destroyed the cable recording station. Subsampling intervals of this length from the complete periods of the time series randomly indicates that there is a $2 \mathrm{~Sv}$ rms error due to linear interpolation. No significant changes to the configuration of the cable monitoring have otherwise occurred during the RAPID time period.

\section{The western boundary wedge}

The western boundary wedge (WBW) is the name given to the continental shelf east of Abaco Island, Bahamas as far as the WB2 mooring at $76.75^{\circ} \mathrm{W}$. This is an array of direct current meters designed to measure the core of the northwards flowing Antilles Current over the quickly changing depths of the continental slope and shelf. The array is used in the AMOC calculation out to WB3 when the WB2 mooring is unavailable. The methodologies involved in the estimation of the transports in the western boundary wedge are extensively described in Johns et al. (2008) and will not be repeated here.

The array measures components of the Antilles Current and the Deep Western Boundary Current in combination from Abaco Island to WB2 (WB3) with a mean strength of $1(-4)$ Sv with a standard deviation of 3 (10) Sv. We note that while the mean transports are small, the variability is large. Inshore of WB2, the northward flowing Antilles Current is the major flow whereas when extending the array out to WB3, the Deep Western Boundary Current plays a dominant role. The transports are directly measured and accurate to within 0.5 (1.5) Sv. The WBW also plays a role in reducing the variability in the calculated AMOC due to eddy noise by making measurements close to the boundary (Kanzow et al., 2009).

\section{Ekman transport at $26^{\circ} \mathrm{N}$}

Ekman transport is the local wind driven transport in the upper ocean (Ekman, 1905), given by

$T_{e k}=-\int \frac{\tau_{x}}{f \rho}$

where $\tau_{x}$ is the zonal component of the wind stress, $f$ is the Coriolis parameter and $\rho$ is the density of seawater. The wind stress is calculated as

$\tau_{x}=\rho_{a} C_{d}|\boldsymbol{u}| u_{x}$,

where $\rho_{a}$ is the density of air, $u$ is the wind speed at a height of $10 \mathrm{~m}$ and $C_{\mathrm{d}}$ is the drag coefficient. $C_{d}$ is defined as $1 \times 10^{-3}$ for wind speeds lower than $7.5 \mathrm{~m} / \mathrm{s}$ and $(0.61+0.063|\boldsymbol{u}|) \times 10^{-3}$ for higher wind speeds (Smith, 1980). This transport is evenly distributed over the top $100 \mathrm{~m}$ in the RAPID calculation.

A number of wind speed data sources have been used to estimate the Ekman transport. These are QuikScat (http://podaac.jpl.nasa.gov/DATA_CATALOG/quikscatinfo.html), CCMP Level 3.0 (Atlas et al., 2011) and ERA-Interim (Dee et al., 2011) winds. QuikScat was the wind product of choice for RAPID publications from Cunningham et al. (2007) to Rayner et al. (2011). Since the demise of the QuikScat scatterometer in November 2009, CCMP has been judged as the best wind product (Kent et al., 2013). Due to operational reasons, there is often a delay on the availability of this product. For this study, ERA-Interim winds are used. Table 3.1 summarises the differences between the three products. At $26^{\circ} \mathrm{N}$, all three products agree well. This is probably due in part to the same data being included in the multiple reanalyses. Only ERA-In- 

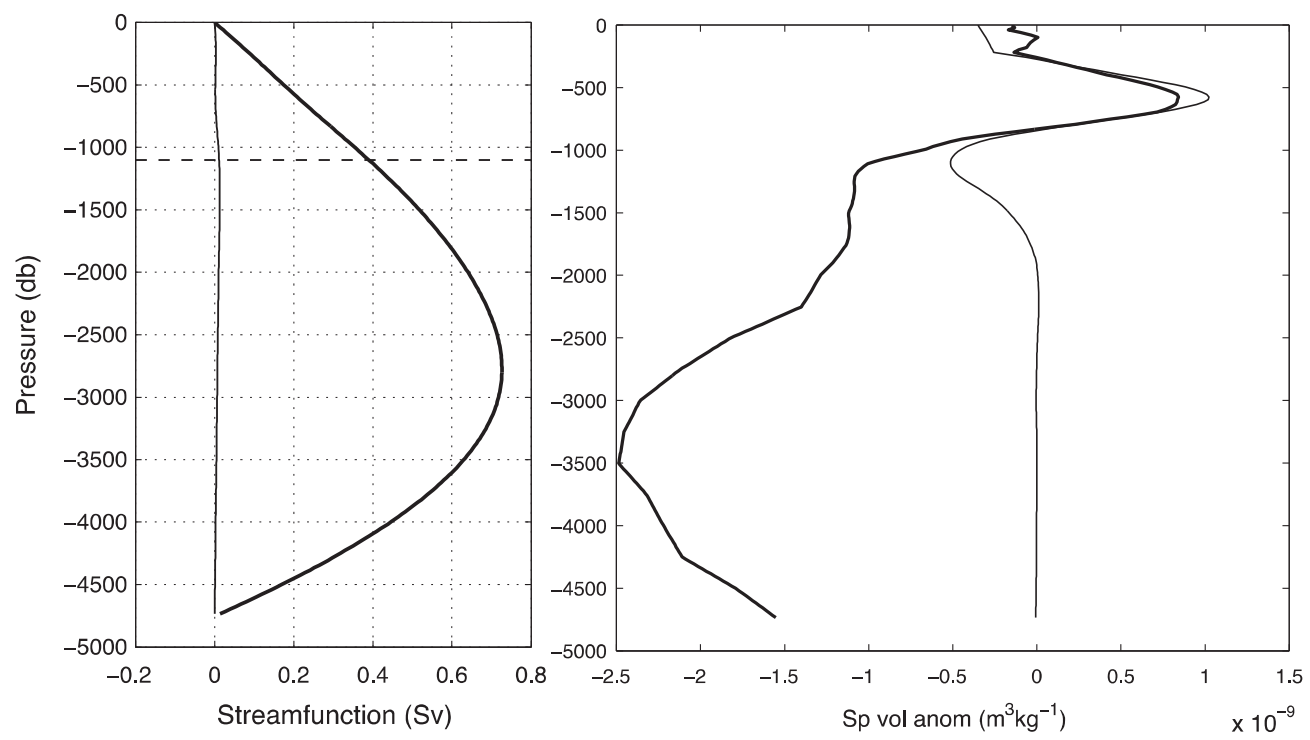

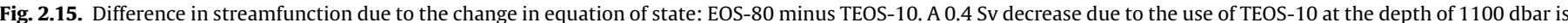

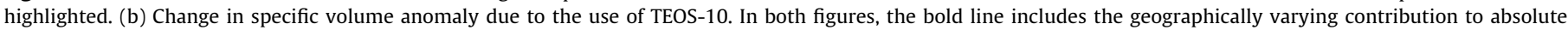
salinity whereas the thin line does not.

terim, on a sparser grid than CCMP and QuikScat, has noticeably less variability.

\section{The external transport: solving for the reference level velocity}

The external transport is the transport added to the internal geostrophic transports so that there is no net meridional flow. Although in reality there is a small net southward transport through the section due to the Bering Strait inflow to the Arctic less the net evaporation-precipitation-runoff, the purpose of requiring zero net mass transport is to isolate the AMOC as a compensated meridional circulation cell that is superimposed on the (weak) net transport through the basin (Bryden and Imawaki, 2001). Since the baroclinic circulation is fully accounted for by the trans-basin array, the residual mass transport has to be carried by depth-independent velocity. It is assumed that the flow is a uniform velocity across the basin so the transport is

$T_{\text {ext }}(z)=v_{\text {comp ref }} \cdot w(z)$,

where $w(z)$ is the width of the basin and $v_{\text {comp,ref }}$ is calculated as the sum of all the transport components (Gulf Stream, Ekman transport, western boundary wedge and the internal geostrophic transport) divided by the area of the section at $26^{\circ} \mathrm{N}$ (not including the Florida Straits). Internal geostrophic transports are calculated relative to a level of no motion at $4820 \mathrm{dbar}$, the deepest common level across the array. The average geostrophic transports shallower than and calculated relative to 4820 dbar across the basin sum to $21 \mathrm{~Sv}$ southwards. While the calculation of external transport is done in a time-varying sense, on average, the $25 \mathrm{~Sv}$ of internal geostrophic southward transport is combined with $32 \mathrm{~Sv}$ Gulf Stream, $3 \mathrm{~Sv}$ Ekman transport, $1 \mathrm{~Sv}$ from the western boundary wedge and $1 \mathrm{~Sv}$ from $A A B W$ (all northwards), to require $12 \mathrm{~Sv}$ (equivalent to a reference level velocity of $0.04 \mathrm{~cm} / \mathrm{s}$ ) of southward external transport to satisfy the constraint of zero net flow.

In a rectangular basin with vertical side walls, $w(z)$ is a constant and the choice of reference level has no effect on the overturning. In a real ocean basin, the external transport does affect the overturning streamfunction due to the narrowing of the basin with depth. Fig. 3.1 shows the bathymetry at $26^{\circ} \mathrm{N}$. Above $3800 \mathrm{~m}$, the basin width is relatively constant; below this depth, the basin narrows substantially due to the presence of the MAR and the sloping eastern boundary. Assuming a depth- and zonally-uniform compensation velocity leads to a external transport profile, $T(z)$, that is proportional to $w(z)$ as shown in Fig. 3.1b, which we refer to as a "hypsometric" compensation profile.

To investigate further the distribution of the hypsometric compensation, we consider five cases.

(a) Reference level at 4820 dbar, approximately the interface between northward flowing AABW and southward flowing lower North Atlantic deep water (NADW).

(b) Reference level at $1200 \mathrm{dbar}$, approximately the interface between northward flowing AAIW and southward flowing upper NADW.

(c) Treating the basin as rectangular-consequently it is insensitive to the choice of reference level. This involves replacing $w(z)$ with $w_{m}$, the mean width of the basin, in Eq. (3.1).

(d) (e) Uses a reference level of 4820 dbar and a basin width profile that puts all the hypsometric compensation to the west (d) and east (e) of $45.5^{\circ} \mathrm{W}$.

Changing the reference level (a, b) varies the total amount of external transport required and so will lead to changes in the shear below $3500 \mathrm{~m}$. While historically, hydrographic section-based estimates of transport use two levels of no motion, a shallower level in the west (near $1200 \mathrm{~m}$, below the AAIW) and deeper level east of this, we are investigating the simpler case of the sensitivity of the AMOC to changing a single reference level. Changing the reference level from 4820 to $1200 \mathrm{~m}$ changes the total mean external transport required to balance mass from $12 \mathrm{~Sv}$ to $22 \mathrm{~Sv}$. Cases (c, $\mathrm{d}$, e) change the profile of the hypsometric compensation but leave the total external transport unchanged.

Fig. 3.2a shows the resulting geostrophic transport for each of the cases. The results are all quite similar. There is little difference between any of the solutions shallower than $3500 \mathrm{~m}$ apart from a small constant offset. An offset of $0.0005 \mathrm{~Sv} / \mathrm{m}$ distributed over the top $4000 \mathrm{~m}$ results in a transport difference of $2 \mathrm{~Sv}$. The different solutions vary less than this for all of the hypsometrically compensated cases (a, b, d, e). The only noticeable difference is in the deep ocean for the rectangular basin (c). This solution deviates from the other solutions in that it removes the shear below $4000 \mathrm{~m}$, where the ocean basin substantially narrows.

Fig. $3.2 \mathrm{~b}$ shows the streamfunctions at $26^{\circ} \mathrm{N}$ resulting from the various solutions (a-e). A larger difference is apparent in the 
streamfunction profiles since the transport differences are accumulated vertically. Nevertheless, all of the hypsometrically compensated cases (a, b, d, e) show similar solutions, none differing by more than $1 \mathrm{~Sv}$ at any depth. Again the rectangular basin solution (c) is the most different as the large differences in transport at depth are accumulated vertically.

The experiments here choose reference levels that are based on interfaces between mean northwards and mean southward flowing water masses and also investigated changing the shape of the compensation profile. The resulting AMOC solutions show a weak dependence on reference level. Using a rectangular basin shape resulted in the largest change to the solution. In this case, the solution artificially removes shear from the deep ocean. We conclude that a hypsometric compensation is more appropriate. Finally, distributing the compensation in the eastern or western basin does not significantly influence the resulting solution. There is a small effect whereby placing all the compensation in the west results in slightly weaker southward flow above the crest of the mid-Atlantic ridge $(3700 \mathrm{~m})$ and slightly stronger southward flow below this depth. The converse is true for placing all the compensation in the east. It is important to note that all of the hypsometric compensations investigated here (cases a, b, d, e) vary by less than the accuracies of the transports discussed elsewhere in this text. This is consistent with Roberts et al. (2013) whose investigations of various reference levels resulted in AMOC variations of less than $2 \mathrm{~Sv}$.

Kanzow et al. (2007) observed a high correlation between transport variability derived from basinwide pressure differences in bottom pressure recorders and transport variability derived by the application of a mass compensation constraint. This result was extended, in a more limited sense, by McCarthy et al. (2012) who observed high correlation between transport variability derived from bottom pressure records on the western boundary and a hypsometrically weighted mass compensation constraint.

These independent bottom pressure observations support the calculation of AMOC variability using a hypsometrically weighted mass compensation. However, we note that the depth structure of this compensation is yet to be fully determined. A difference between some models and observations, highlighted by Roberts et al. (2013), lies in the deep overturning streamfunction. Many models (e.g. FOAM (Roberts et al., 2013) and HYCOM (Xu et al., 2012)) show a more vigorous and shallower deep overturning cell than RAPID (e.g. Roberts et al., 2013, Fig. 1; Xu et al., 2012, Fig. 6). Roberts et al. (2013) showed that agreement between FOAM and the observations could be recovered by calculating the AMOC in the model using the RAPID methodology. This provides a method of comparing like-with-like in terms of the depth structure of the overturning streamfunction. In an analysis of bottom pressure measurements, Kanzow (personal communication) has found that the deep compensation may be more vigorous than that derived from the hypsometric compensation described here. While the impact of this deep compensation is a topic of ongoing research, it is unlikely to change the final value of the AMOC by more than $1 \mathrm{~Sv}$.

\section{The atlantic meridional overturning circulation}

The value of the AMOC is defined as the maximum of the transport streamfunction when all the components are combined. The full time-varying transport streamfunction is given by:

Table 3.1

Mean, standard deviations of Ekman transports of the QuikScat, CCMP and ERAInterim wind products for the period April 2004 to November 2009 in units of Sv.

\begin{tabular}{llll}
\hline & QuikScat & CCMP & ERA-Interim \\
\hline Mean & 3.6 & 3.6 & 3.8 \\
Std. dev. & 3.4 & 3.3 & 2.9 \\
\hline
\end{tabular}

$\Psi(t, z)=\int^{z}\left\{T_{f l o}(t, z)+T_{e k}(t, z)+T_{w b w}(t, z)+T_{\text {int }}(t, z)+T_{e x t}(t, z)\right\} d z$

where $\Psi$ is the transport streamfunction. Subscripts $f l o, e k$, and wbw refer to the transport in the Florida Straits, Ekman transport and western boundary wedge. $T_{\text {int }}$ is the internal geostrophic transports derived from Eq. (1.4). $T_{\text {ext }}$ is the hypsometric mass compensation as described in the previous section. The mid-ocean transport is defined as the sum of $T_{i n t}, T_{\text {ext }}$ and $T_{w b w}$. $T_{\text {int }}$ includes the new time-invariant AABW profile discussed previously. The mean component transports per unit depth are shown in Fig. 4.1.

The AMOC is defined as the maximum of this streamfunction integrating down from the surface:

$\operatorname{AMOC}(t)=\Psi\left(t, z_{\max }\right)$,

where $z_{\max }$ is the depth of the maximum of the transport streamfunction. Fig. 4.2 shows the transport streamfunction at each time step with the strength and depth of the AMOC overlaid.

The AMOC has two depth modes as seen in Fig. 4.2. When northward flowing Antarctic Intermediate Water (AAIW) is present, the depth of the maximum AMOC is close to $1100 \mathrm{~m}$. When no AAIW flows north, the depth of the maximum AMOC is close to $700 \mathrm{~m}$ : the depth of the Florida Straits. We use this depth criteria to define the AMOC when no water flows northward, such as occurred in December 2009 (McCarthy et al., 2012). In this instance, we define the AMOC as the integral of the component transports to either $1100 \mathrm{~m}$, when northward flowing AAIW exist, or to $700 \mathrm{~m}$, when no northward flowing AAIW exists.

The upper mid-ocean transport is defined as the mid-ocean transports integrated from the surface down to the depth of the maximum AMOC. When the depth of the AMOC is greater than the depth of the Florida Straits, the sum of the total Florida Straits, Ekman and upper mid-ocean transports is equal to the strength of the AMOC.

The 8.5 year timeseries from April 2004 to October 2012, shown in Fig. 4.3, has a mean strength of $17.2 \mathrm{~Sv}$ with a 10 day filtered rms variability of $4.6 \mathrm{~Sv}$. This mean AMOC transport is lower than earlier estimates mainly due to the decreasing strength of the AMOC over the length of the record (Smeed et al., 2014). A smaller contribution to the lower mean AMOC transport value is due to the improvements to the AMOC calculation methodology described in this paper that have resulted in a reduced mean strength of the overall AMOC of $0.6 \mathrm{~Sv}$.

\section{The meridional heat transport}

The meridional heat transport (MHT) carried across a transbasin section at any latitude is given by (Jung, 1952; Bryan, 1982):

$Q=\int_{x_{w}}^{x_{e}} \int_{H}^{0} \rho c_{p} v \theta d x d z$

where $\rho$ is seawater density, $c_{p}$ is the specific heat of seawater, $v$ is meridional velocity, $\theta$ is potential temperature, and where the double integral is taken over the full depth $(H)$ of the trans-basin section between eastern $\left(x_{e}\right)$ and western $\left(x_{w}\right)$ boundaries. Johns et al. (2011) produced estimates of the MHT across $26.5^{\circ} \mathrm{N}$ by breaking this total heat transport down into a number of separate components of temperature transport (relative to a common temperature reference), which are then summed together to derive the total MHT. The breakdown used here is:

$Q_{N E T}=Q_{F C}+Q_{E K}+Q_{W B W}+Q_{M O}+Q_{E D D Y}$,

where the different terms represent, respectively, the meridional temperature transports of the Florida Current $\left(Q_{F C}\right)$, the Ekman layer $\left(Q_{E K}\right)$, the western boundary wedge $\left(Q_{W B W}\right)$, the zonally-averaged 

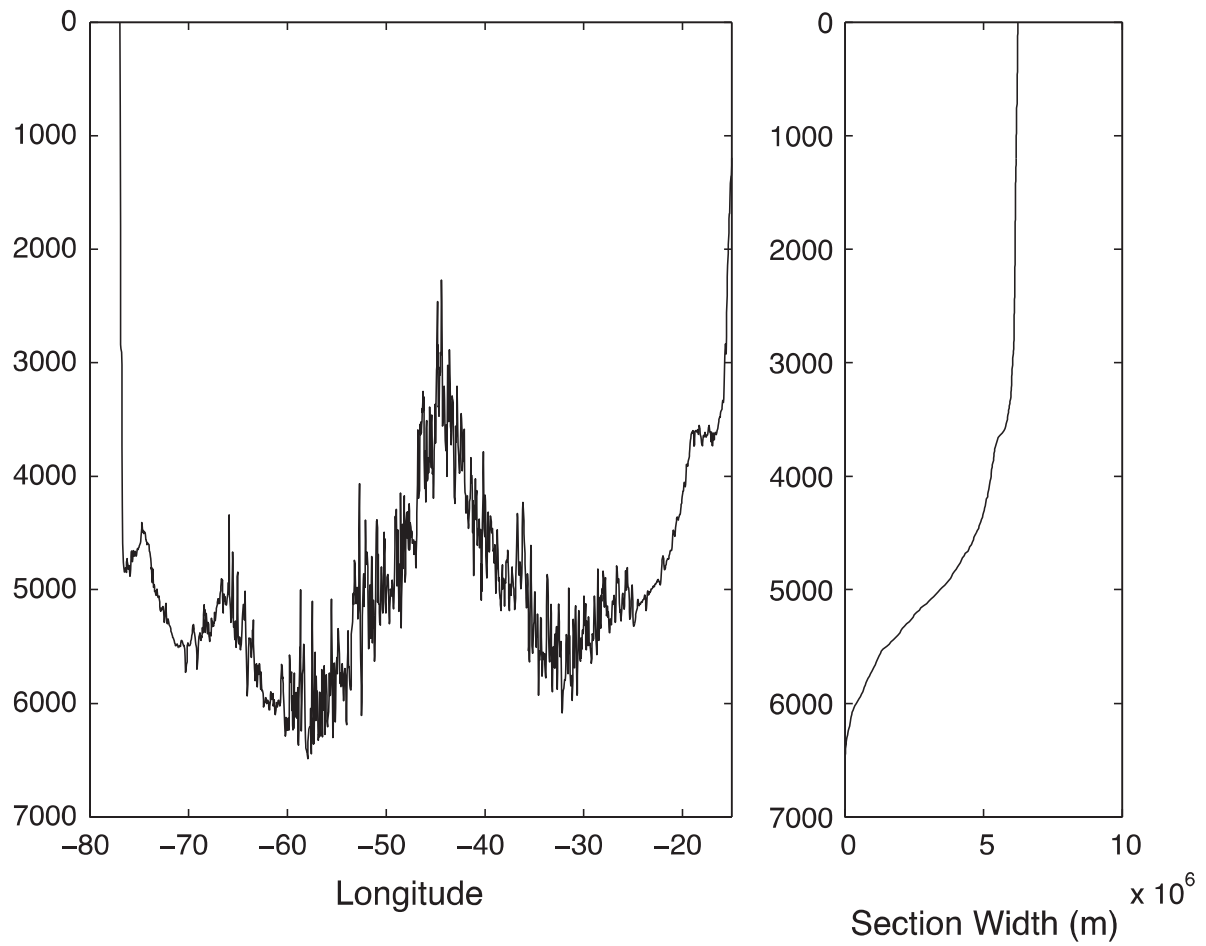

Fig. 3.1. (Left) Bathymetry at $26^{\circ} \mathrm{N}$ and (right) derived basin width.

contribution by the mid-ocean circulation $\left(Q_{M O}\right)$, and the mid-ocean "eddy" contribution due to spatially correlated $v$ and $\theta$ fluctuations $\left(Q_{E D D Y}\right)$. The latter term is a true heat transport since it has no mass transport associated with it and is independent of temperature reference.

The methodology by which each of these terms is estimated is described thoroughly in Johns et al. (2011) and we will only briefly review these here. In addition to the updated methods for

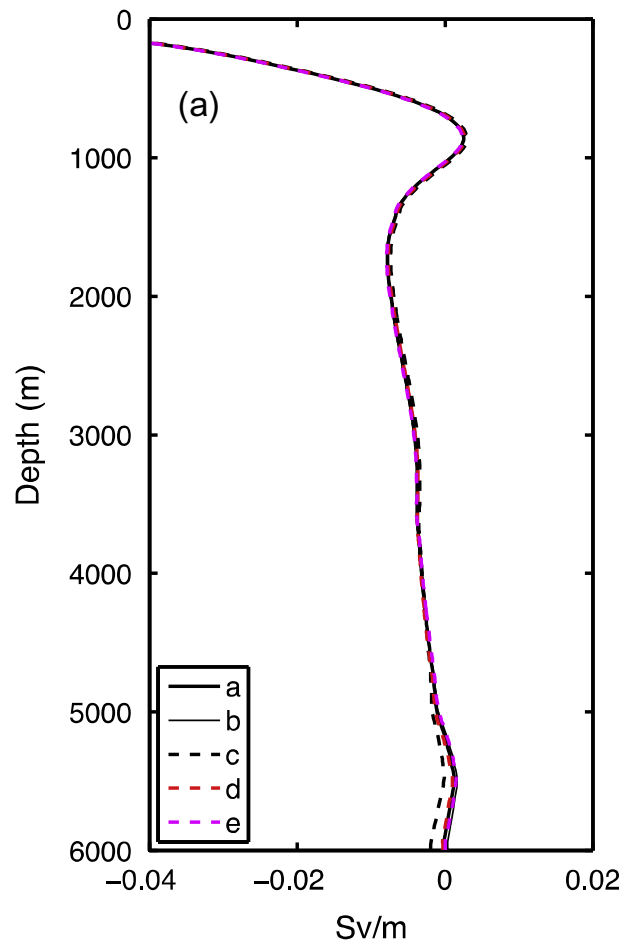

computing the AMOC mid-ocean transport and the Ekman transports, changes to the calculations of Johns et al. (2011) include the following:

1. The Ekman heat transport is now calculated using ERA-Interim winds and the interior ocean temperature profiles derived from Argo (see 2 below), where the Ekman transport is essentially assumed to be confined to the upper $50 \mathrm{~m}$ of the water column.

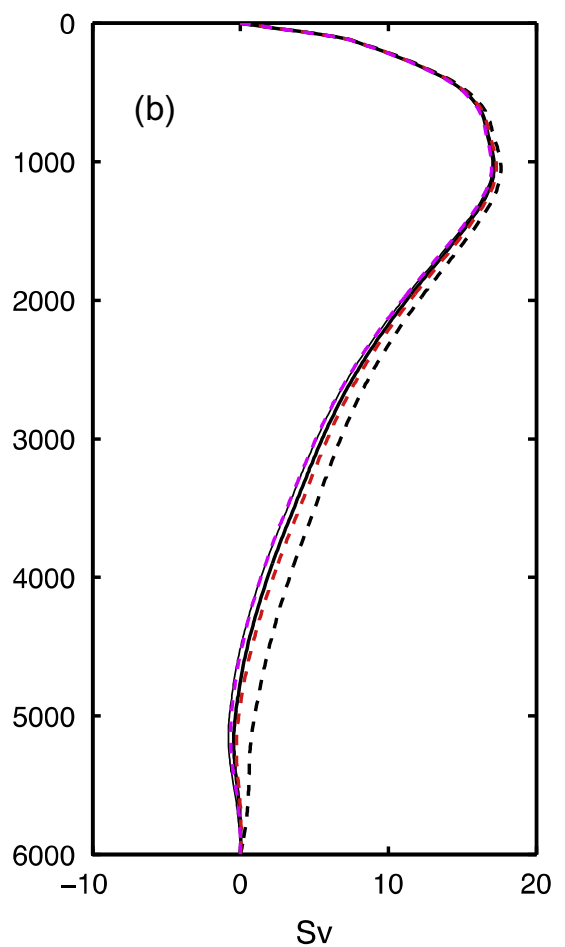

Fig. 3.2. (a) Mid-ocean transport profiles derived from the five cases described in the text. (b) Transport streamfunction including mid-ocean, Florida Straits and Ekman transports. 


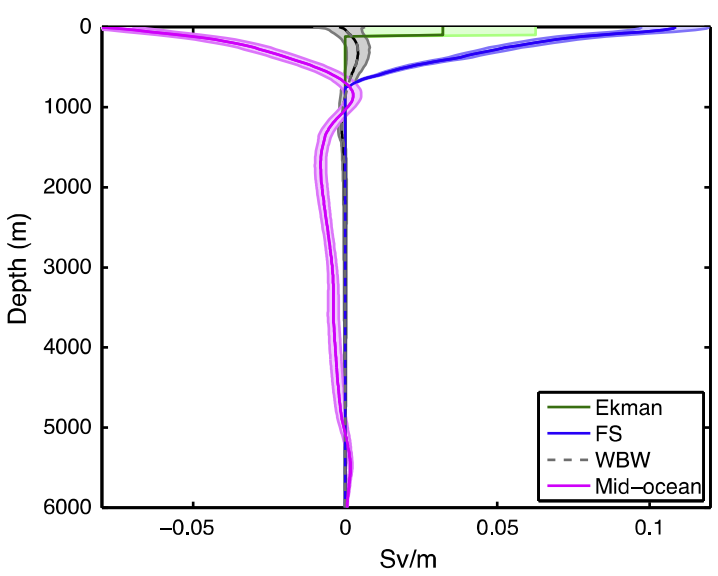

Fig. 4.1. Mean (solid lines) and standard deviations (shading) component transport per unit depth of the circulation derived from the RAPID calculation: (green) Ekman transports, (blue) Florida Straits transport, (grey, dashed) western boundary wedge and (magenta) full geostrophic mid-ocean transports. (For interpretation of the references to colour in this figure legend, the reader is referred to the web version of this article.)

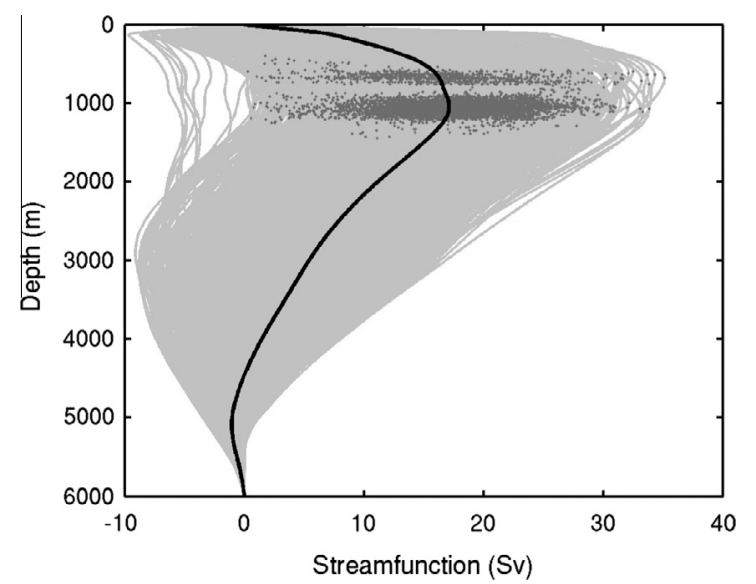

Fig. 4.2. AMOC streamfunctions: all (grey), mean (black) and AMOC values (grey dots).
Thus the Ekman layer temperature is a weighted average of the upper $50 \mathrm{~m}$ temperatures. Previously we had used Reynolds SST's in the interior and assumed the Ekman layer temperature to be equal to the Reynolds SST. We estimate that averaging over the top $50 \mathrm{~m}$ gives an estimate of $0.005 \mathrm{PW}$ lower than the SST based estimate, with all of the difference occurring in the summer-the only time the mixed layer depth is less than $50 \mathrm{~m}$. Distribution of the Ekman heat transport over the top $50 \mathrm{~m}$ is consistent with Hall and Bryden (1982), who used a weighted temperature average over the top $50 \mathrm{~m}$, and with the findings of Wijffels et al. (1994), who found that all of Ekman transport occurred within $0.2^{\circ} \mathrm{C}$ of the SST value.

2. The mid-ocean "eddy" heat flux $Q_{E D D Y}$ is derived from an objective analysis of available Argo data profiles in the interior combined with $\mathrm{T} / \mathrm{S}$ profiles from the RAPID moorings. This objective analysis (OA) product is produced internally by the RAPID program, based on Argo and moorings data, at weekly temporal resolution. Argo data has good coverage at this latitude (approximately 40 profiles per month from 2004 to 2006 and more than 100 profiles per month from 2008), allowing accurate determination of the internal temperature and salinity fields. Meridional velocity anomalies across the section are derived from this OA using a geostrophic approximation relative to $1000 \mathrm{~m}$. Previously, $Q_{E D D Y}$ had been calculated from a "piecewise" mooring approach (also relative to $1000 \mathrm{~m}$ ) using only the mooring data across the section, as described in Johns et al. (2011) and, as such, the principal improvement here is the increase in resolution across the section provided by the Argo floats. The two approaches agree within error bars and are consistent with the range of estimates available from transbasin hydrographic sections along $26^{\circ} \mathrm{N}$. As noted in Johns et al. (2011), this "eddy" heat flux is actually associated mainly with the large-scale structure of $v$ and $T$ anomalies across the subtropical gyre, rather than mesoscale features. The Argo data are therefore able to resolve it adequately even at relatively coarse resolution across the section.

3. The interior zonal average temperature transport $Q_{M o}$ now uses a time varying interior temperature field derived from the Argo and RAPID mooring data as above, merged into a seasonal temperature climatology below $2000 \mathrm{~m}$ based on the RAPID HydroBase product described in Johns et al. (2011). Previously the

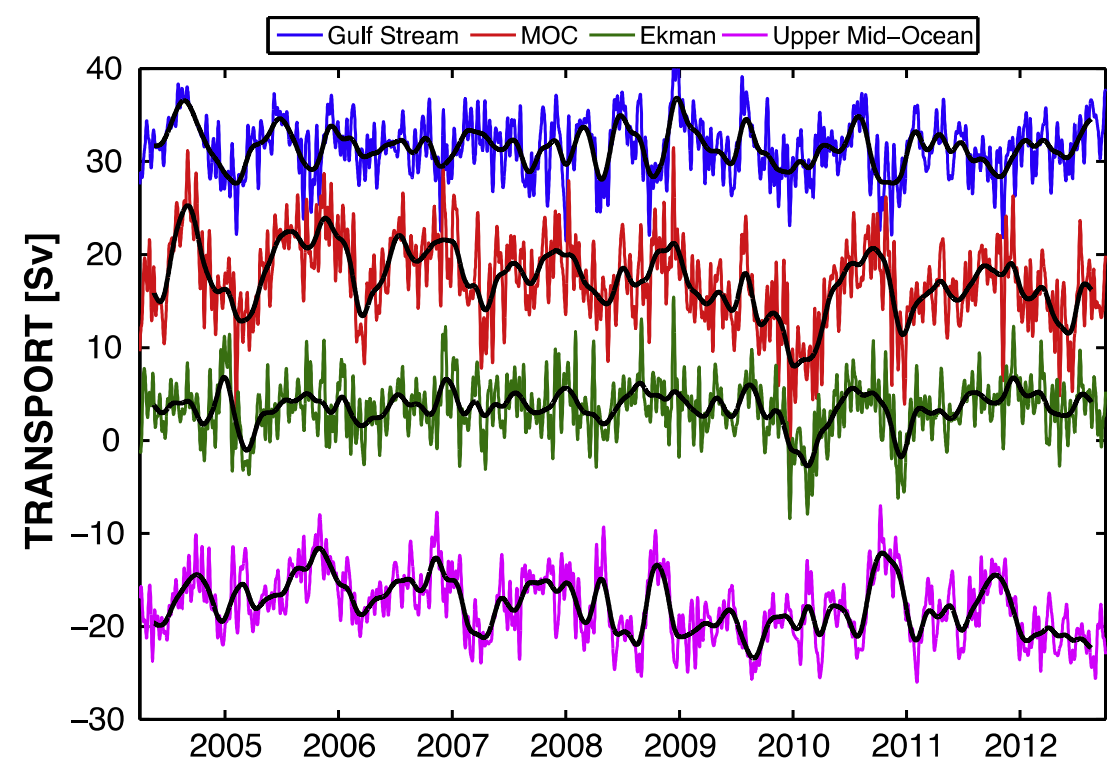

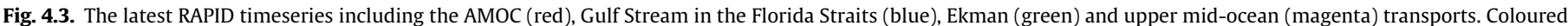

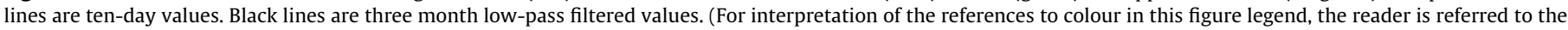
web version of this article.) 
interior zonal mean temperature field was taken only from the seasonally varying RAPID HydroBase climatology.

The updated time series of the MHT is shown in Fig. 5.1, where the three contributions in the mid-ocean region $\left(Q_{M O}, Q_{W B W}\right.$, and $\left.Q_{E D D Y}\right)$ are combined into one term. There is overall a very close correspondence between the MHT time series and the AMOC time series, where the MHT reaches low values in the winters of 2009/10 and 2010/11 during the corresponding low AMOC events.

Accuracies of the individual components and the total MHT are given in Table 5.1, along with their mean values, standard deviations, and standard errors over the 8.5 year record obtained to date (April 2004-October 2012). The overall accuracy of the daily mean MHT estimate is $0.21 \mathrm{PW}$, which is about a factor of two smaller than its standard deviation of $0.36 \mathrm{PW}$. The error variance associated with this random measurement uncertainty $\left(0.21^{2}=0.04 \mathrm{PW}^{2}\right)$ is thus about one-third of the actual sample variance of the MHT time series $\left(0.36^{2}=0.13 \mathrm{PW}^{2}\right)$. The integral time scale of the MHT timeseries is 29 days, and so this gives 53 degrees of freedom, assuming one independent measurement for each two integral timescales. The overall statistical uncertainty in the mean MHT estimate is therefore dominated by the intrinsic MHT variability. The standard error of the mean MHT over the 8.5 year record is $0.05 \mathrm{PW}$, which is reduced significantly due to the long length of the record. A bias error of up to $0.06 \mathrm{PW}$ is added to this statistical error to account for possible sampling and computational biases in the observing system, as outlined in (Johns et al., 2011), leading to a total error for the mean MHT of $0.11 \mathrm{PW}$, or about $10 \%$ of the measured mean value of $1.25 \mathrm{PW}$.

As described in Johns et al. (2011), the RAPID data can also be used to determine the "overturning" and "gyre" components of the MHT, which are defined by (Bryan, 1982; Böning and Herrmann, 1994):

$Q_{O T}=\int \rho c_{p}\langle V\rangle\langle\theta\rangle d z$
Table 5.1

Summary of statistics for the total MHT and its components as measured by the RAPID array. Temperature transports (multiplied by $\rho c_{p}$ ) are computed relative to $0{ }^{\circ} \mathrm{C}$ ( $Q_{E D D Y}$ and $Q_{T O T}$ are independent of temperature reference). The mean values reflect the averages from April 2004 to October 2012. In computing the standard errors of the mean quantities, the number of degrees of freedom is estimated by dividing the record length by twice the integral time scale of the variability of the respective quantity (Johns et al., 2011).

\begin{tabular}{lclll}
\hline \multirow{2}{*}{ MHT component } & \multicolumn{4}{c}{ Temperature or heat transport (PW) } \\
\cline { 2 - 5 } & Mean value & Std. dev. & Meas. error & Std. error \\
\hline$Q_{F C}$ & 2.51 & 0.25 & 0.12 & 0.03 \\
$Q_{E K}$ & 0.35 & 0.29 & 0.11 & 0.03 \\
$Q_{W B}$ & 0.12 & 0.18 & 0.02 & 0.02 \\
$Q_{M O}$ & -1.81 & 0.31 & 0.13 & 0.04 \\
$Q_{E D D Y}$ & 0.08 & 0.03 & 0.03 & 0.01 \\
$Q_{T O T}$ & 1.25 & 0.36 & 0.21 & 0.05 \\
\hline
\end{tabular}

$Q_{G Y R E}=\iint \rho c_{p}^{*} \theta^{*} d x d z$

where angle brackets now represent the zonal average across the entire transoceanic section (from Florida to Africa), asterisks represent the deviations from these zonal means, and $V$ is the transport per unit depth profile. These heat transports represent the heat fluxes carried by individually mass-conserving vertical ("overturning") and horizontal ("gyre") cells, where the former is also sometimes called the baroclinic heat transport (Bryden and Imawaki, 2001). The breakdown into the overturning and gyre MHT components is shown in Fig. 5.2, where it is clear that approximately $90 \%$ of the heat transport-and an even higher proportion of the interannual variability observed thus far-is contained in the overturning component. The gyre component on the other hand shows a fairly regular seasonal cycle which is mainly dominated by the annual cycle of the Florida Current.

A natural companion of the MHT estimates is the estimation of continuous freshwater fluxes across the section using the moored

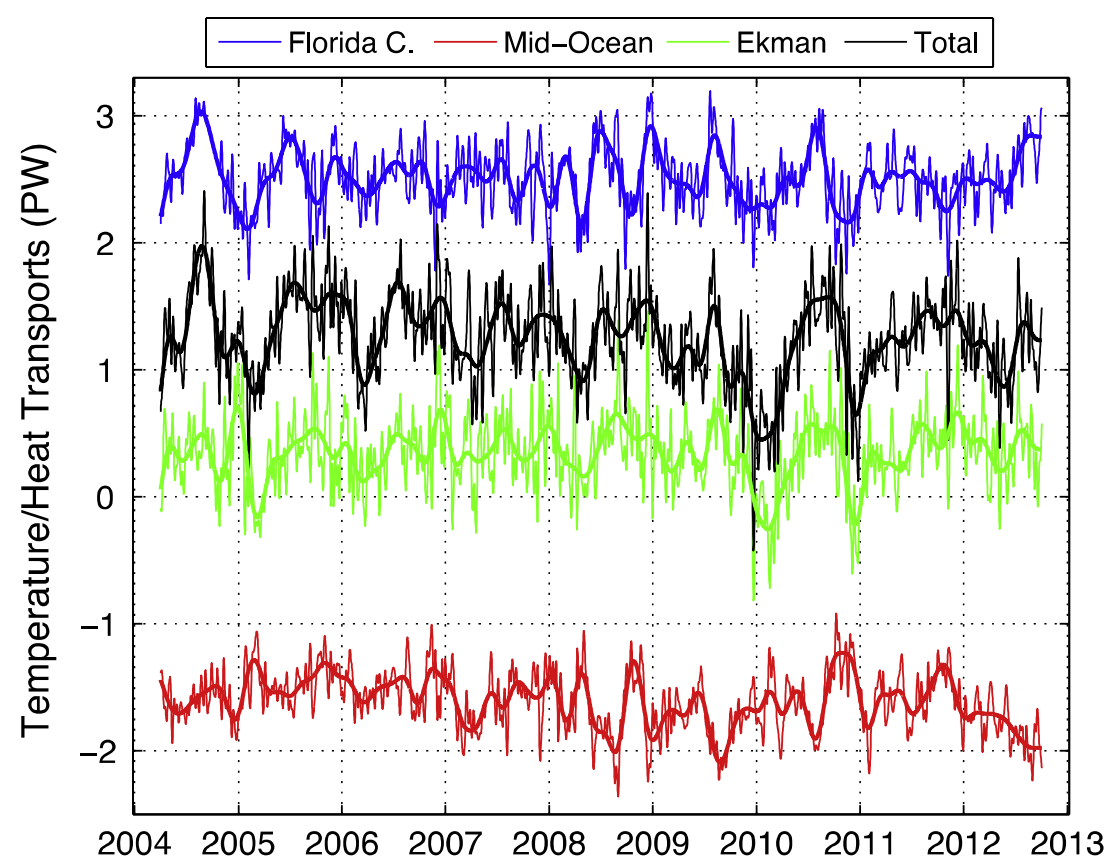

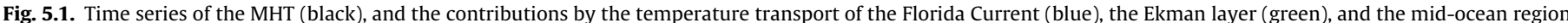

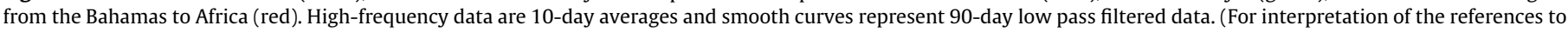
colour in this figure legend, the reader is referred to the web version of this article.) 


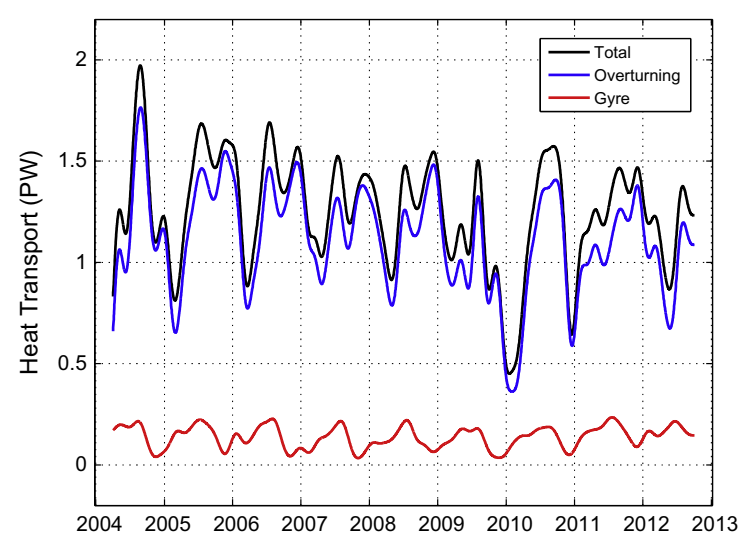

Fig. 5.2. Breakdown of the total MHT (black) into its "overturning" (blue) and "gyre" (red) components; see text for definitions. The curves shown are 90-day low pass filtered values. (For interpretation of the references to colour in this figure legend, the reader is referred to the web version of this article.)

Table 6.1

Summary of the errors associated with the components and calculation of the AMOC.

\begin{tabular}{lll}
\hline (Sv) & $\begin{array}{l}\text { RMS error: } \\
\text { 10 day values }\end{array}$ & $\begin{array}{l}\text { RMS error: } \\
\text { annual values }\end{array}$ \\
\hline AMOC & 1.5 & 0.9 \\
Geostrophic transports & 0.9 & 0.7 \\
$\begin{array}{l}\text { Accuracy of temperature and salinity } \\
\quad \text { measurements }\end{array}$ & 0.8 & 0.6 \\
Gridding error & 0.4 & 0.4 \\
Other components & & \\
Western boundary wedge & 0.5 & 0.5 \\
Gulf Stream in Florida Straits & 1.1 & 0.3 \\
\hline
\end{tabular}

array. The initial analysis of this is described in McDonagh et al. (submitted for publication) and will not be discussed further here.

\section{Summary and conclusions}

In this paper we have reviewed and discussed the AMOC measurements at $26^{\circ} \mathrm{N}$, including improvements to the calculation of the AMOC and MHT since Rayner et al. (2011) and Johns et al. (2011). We have made detailed estimates of the uncertainties (Table 6.1) and described improvements to the calculation of the AMOC-by use of a better shear extrapolation technique, improved AABW profile and the use of the new equation of state TEOS-10and MHT-by using an Argo and mooring climatology to improve estimation of Ekman, eddy and mid-ocean temperature transports. As these observations are frequently used for model comparison and validation, it is important that the details and errors in the observations are understood.

The AMOC calculation at $26^{\circ} \mathrm{N}$ takes advantage of the geostrophic balance to use a relatively sparse array of moorings to measure the northward flow. The latitude of $26^{\circ} \mathrm{N}$ is an ideal location for a basinwide AMOC monitoring array for two main reasons: firstly, the measurement of the Gulf Stream in the Florida Straits (Baringer and Larsen, 2001) defines the western boundary current and, secondly, the steep continental shelf off the Bahamas suppresses westward propagating mesoscale features and allows for estimates of transport representative of the basinwide flow (Kanzow et al., 2009).

This method relies on accurate profiles of dynamic height anomaly, derived from temperature, salinity and pressure measurements from moored instruments. The accuracy of the instruments themselves is improved by a careful process of ship-board calibration (Kanzow et al., 2006). This results in temperature, salinity and pressure measurements accurate to $0.002{ }^{\circ} \mathrm{C}, 0.003$ and 1 dbar, respectively. Of these measurements, it is salinity that is the largest source of error in the calculated AMOC due to potential biases in the calibration process. Temperature and pressure errors of $0.002{ }^{\circ} \mathrm{C}$ and $1 \mathrm{dbar}$ have a smaller impact on the estimated AMOC than a salinity error of 0.003 . We estimate an rms uncertainty of $0.8 \mathrm{~Sv}$ due to calibration issues.

There are around 20 instruments on a typical full depth mooring. These need to be interpolated on to a high resolution vertical grid to construct useful dynamic height anomaly profiles. We use the method of Johns et al. (2005) based on the gradients of temperature and salinity to interpolate the sparse instruments onto a high resolution grid. There is an rms uncertainty of $0.4 \mathrm{~Sv}$ in estimating the AMOC due to this procedure. While this rms uncertainty in the AMOC is small, the estimated maximum gridding inaccuracies of $0.05^{\circ} \mathrm{C}$ in temperature in the thermocline are 25 times larger than the accuracy with which temperature can be determined. In comparison, a maximum gridding inaccuracy of 0.01 in salinity is only 3 times larger than the accuracy with which salinity can be determined. For a different application, interspersing some cheaper temperature-only instruments between the moored CTDs might be considered so that errors due to gridding are reduced relative to the accuracy of the measurement.

The errors associated with gridding and calibration of the dynamic height moorings are combined with the errors in the Gulf Stream transport, western boundary wedge and Ekman transports to give an overall estimate of the error for the estimated AMOC. The 10-day estimations of the AMOC have an rms uncertainty of $1.5 \mathrm{~Sv}$ (Table 6.1). We have also considered uncertainties in annual averages. The errors do not drop dramatically for annual averages due to the nature of the uncertainties. When the full array is operational, an annual rms uncertainty of $0.9 \mathrm{~Sv}$ is estimated. This can increase when mooring losses occur. The mooring losses that have occurred only significantly influence the error estimate in 2005 and 2007, when the WB2 mooring failed and mini-mooring losses on the eastern boundary respectively increased the estimated annual rms uncertainty to $1.1 \mathrm{~Sv}$ and $1.4 \mathrm{~Sv}$.

The shallowest and deepest measurements present particular challenges. The practicalities of deploying a mooring in the real ocean mean that measurements shallower than $100 \mathrm{~m}$ are often absent. Haines et al. (2013) compared the RAPID measurements with a data assimilating model and found that linear extrapolation above the shallowest measurements in RAPID failed to capture $1.5 \mathrm{~Sv}$ of southward transport in the late summer in the top $150 \mathrm{~m}$. Here, we have implemented a seasonally varying extrapolation technique that captures additional southward transport due to the shallow seasonal thermocline.

The deepest measurements pose a challenge due to the large pressures, remote location and often highly variable topography that the moorings are deployed in. Moorings have been successfully deployed to measure deep ( $>4820$ dbar) transport for a duration of 2 years. The variability of the estimated AMOC changed by $\pm 0.2 \mathrm{~Sv}$ when these deep moorings were included in the calculation. While the variability observed was small, the continuous measurements lead to improvements to the mean shape and strength of the transport profile. Consequently a new mooringsbased time-invariant transport profile has replaced the previous hydrography-based transport profile. The new profile fixes transport deeper than 4820 dbar to $1 \mathrm{~Sv}$. This transport is not directly comparable to AABW transport as the 4820 dbar delimiter differs from the standard $1.8^{\circ} \mathrm{C}$ potential temperature isotherm often used in hydrographic studies (Frajka-Williams et al., 2011). Even so, these seemingly low estimates of AABW transport coincide with changes in the deep overturning cell. Hydrographic estimates of AABW transport since 1957 at $24^{\circ} \mathrm{N}$ suggested that transport in these deeper layers used to be stronger (Johnson et al., 2008). 
Purkey and Johnson (2012) used hydrography to estimate largescale changes in transport of the deep overturning cell from 1993 to 2006, giving a reduction of the deep overturning cell by as much as $8.2 \mathrm{~Sv}$ over this 13 year period. While the previous hydrographic section-based estimates of transport are subject to issues of aliasing when used to quantify transport variability, the present estimates from the RAPID array supports the observations that AABW transport is lower than it has been in the past.

The AMOC at $26.5^{\circ} \mathrm{N}$ is now calculated using TEOS- 10 , the new equation of state for seawater. The introduction of the geographical variations in absolute salinity primarily driven by silicate concentrations were found to have a non-negligible effect on the calculation of the density gradient across the basin and hence the AMOC. The AMOC, as estimated using TEOS-10, is $0.4 \mathrm{~Sv}$ weaker than using EOS- 80 . This $2 \%$ change is of the order of predicted changes to basinwide transports when transitioning to the new equation of state (IOC et al., 2010). Estimates of circulation strength throughout the world's oceans will need to be revised by similar amounts due to this new equation of state, with some regions changing more than others.

The use of a hypsometric mass compensation, taking account of the narrowing of the basin with depth, to reference the internal geostrophic transports introduces a dependence on the choice of reference level for the resulting overturning estimate (Roberts et al., 2013). Here, we have compared a number of choices of reference level and shapes of hypsometric transport profiles. We conclude that the impact on the estimated strength of the AMOC due to choice of reference level is less than $1 \mathrm{~Sv}$, which is comparable to the accuracy of the calculation. There is some uncertainty in the magnitude of the deep transport and this is a topic of ongoing research.

The calculation of the AMOC is made by combining the Gulf Stream, western boundary wedge, Ekman and mass-compensated geostrophic transports together to get an overall basinwide transport profile. This is integrated vertically to get a transport streamfunction, the maximum of which is defined as the strength of the AMOC. The AMOC has a strength of 17.2 Sv from April 2004 to October 2012. This is lower than the estimate of $18.7 \mathrm{~Sv}$ for the first year of measurements in 2004 (Cunningham et al., 2007) mainly due to an observed decline in the strength over the period of observation (Smeed et al., 2014) and also due to improvements to the calculation detailed in this text that have reduced the strength of the AMOC by $0.6 \mathrm{~Sv}(-0.4 \mathrm{~Sv}$ due to the new extrapolation above the shallowest measurement, $+0.2 \mathrm{~Sv}$ due to the new AABW transport, $-0.4 \mathrm{~Sv}$ due to the new equation of state).

The calculation of the MHT is more difficult than the AMOC as it needs, in principle, the covariances of temperature and velocity across the section. Here, we have presented an update to the methods of Johns et al. (2011) by incorporation of time-varying Argo temperature and velocity fields in the calculation of the mid-ocean, Ekman and eddy heat flux terms. Changes in the calculation of the AMOC also have implications for heat transport. Specifically, Haines et al. (2013) highlighted a 0.1 PW lower MHT in a high resolution ocean model compared to RAPID caused by disagreement in the top $100 \mathrm{~m}$ transport. Improvements to the surface extrapolation have reduced the mean MHT by $0.04 \mathrm{PW}$ (maximum reduction of $0.07 \mathrm{PW}$ in October; minimum of $0.01 \mathrm{PW}$ in January). This change is smaller than that found by Haines et al. (2013) but in line with the reduction in the AMOC described in this manuscript. Overall, the reduction in the mean value of the MHT from 1.33 PW to 1.25 PW published by Johns et al. (2011) was mainly due to very low heat transport in 2009 and 2010 (Cunningham et al., 2013) and also the decline in AMOC transports over the ten years (Smeed et al., 2014), rather than changes in methodology.

The AMOC monitoring project at $26^{\circ} \mathrm{N}$ has revolutionised our understanding of the variability and structure of the AMOC on sub-annual (Cunningham et al., 2007), seasonal (Kanzow et al., 2010; Chidichimo et al., 2010) and interannual (McCarthy et al., 2012) timescales. It has provided the first continuous estimates of heat transports across an ocean basin (Johns et al., 2011). Smeed et al. (2014) have presented the first multi-year trend analysis of the timeseries. The $26^{\circ} \mathrm{N}$ measurements were the first full ocean depth, basinwide, continuous in time estimates of the AMOC and it is hoped that the detailed description of the calculation and discussion of the associated errors in this manuscript will contribute to greater understanding of these AMOC and MHT estimates.

\section{Acknowledgements}

The RAPID/MOCHA/WBTS array is a collaborative effort supported through the UK Natural Environment Research Council (NERC) RAPID-WATCH program, the US National Science Foundation (NSF) Meridional Overturning Circulation Heat-flux Array project, and the US National Oceanographic and Atmospheric Administration (NOAA) Western Boundary Time Series project. AMOC transport estimates including error estimates are freely available from www.rapid.ac.uk/rapidmoc. Florida Current transports estimates are available from www.aoml.noaa.gov/phod/floridacurrent. MHT estimates can be found online at http:// www.rsmas.miami.edu/users/mocha.

\section{References}

Atlas, R., Hoffman, R.N., Ardizzone, J., Leidner, S.M., Jusem, J.C., Smith, D.K., Gombos, D., 2011. A cross-calibrated, multiplatform ocean surface wind velocity product for meteorological and oceanographic applications. Bulletin of the American Meteorological Society 92, 157-174.

Baehr, J., Hirschi, J., Beismann, J.-O., Marotzke, J., 2004. Monitoring the meridional overturning circulation in the North Atlantic: a model-based array design study. Journal of Marine Research 62, 283-312.

Baringer, M.O., Larsen, J.C., 2001. Sixteen years of Florida Current transport at $27^{\circ}$ N. Geophysical Research Letters 28, 3182-3197.

Baumgartner, A., Reichel, E., 1975. The World Water Balance: Mean Annual Global, Continental and Maritime Precipitation Evaporation and Run-off. Elsevier Scientific, 179pp.

Beal, L.M., Bryden, H.L., 1999. The velocity and vorticity structure of the Agulhas Current at 32 S. Journal of Geophysical Research: Oceans (1978-2012) 104, $5151-5176$.

Bennett, A., 1978. Poleward heat fluxes in southern hemisphere oceans. Journal of Physical Oceanography 8, 785-798.

Blaker, A.T., Hirschi, J.J.-M., McCarthy, G.D., Sinha, B., Taws, S.L., Marsh, R., Coward, A., de Cuevas, B., 2014. Historical analogues of the recent extreme minima observed in the Atlantic meridional overturning circulation at $26^{\circ} \mathrm{N}$. Climate Dynamics, 1-17.

Böning, C.W., Herrmann, P., 1994. Annual cycle of poleward heat transport in the ocean: results from high-resolution modeling of the North and equatorial Atlantic. Journal of Physical Oceanography 24, 91-107.

Broeker, W.S., 1991. The great ocean conveyor. Oceanography 4, 79-89.

Bryan, K., 1982. Seasonal variation in meridional overturning and poleward heat transport in the Atlantic and Pacific Oceans: a model study. Journal of Marine Research 40, 39-53.

Bryden, H.L., Hall, M.M., 1980. Heat transport by currents across $25 \mathrm{~N}$ latitude in the Atlantic Ocean. Science 207, 884-886.

Bryden, H.L., Imawaki, S., 2001. Ocean heat transport. In: Siedler, G. et al. (Eds.), Ocean Circulation and Climate: Observing and Modelling the Global Ocean. International Geophysics Series 77. Academic Press, pp. 455-474.

Bryden, H.L., Longworth, H.R., Cunningham, S.A., 2005. Slowing of the Atlantic meridional overturning circulation at $25^{\circ} \mathrm{N}$. Nature 438, 655-657.

Bryden, H.L., Mujahid, A., Cunningham, S.A., Kanzow, T., 2009. Adjustment of the basin-scale circulation at $26^{\circ} \mathrm{N}$ to variations in Gulf Stream, deep western boundary current and Ekman transports as observed by the RAPID array. Ocean Science 5, 421-433.

Bryden, H.L., King, B.A., McCarthy, G.D., McDonagh, E.L., 2014. Impact of a 30\% reduction in Atlantic meridional overturning during 2009-2010. Ocean Science Discussions 11, 789-810.

Chidichimo, M.P., Kanzow, T., Cunningham, S.A., Johns, W.E., Marotzke, J., 2010. The contribution of eastern-boundary density variations to the Atlantic meridional overturning circulation at $26.5^{\circ} \mathrm{N}$. Ocean Science $6,475-490$.

Cunningham, S.A., Kanzow, T., Rayner, D., Baringer, M.O., Johns, W.E., Marotzke, J., Longworth, H.R., Grant, E.M., Hirschi, J.J.-M., Beal, L.M., Meinen, C.S., Bryden, H.L., 2007. Temporal variability of the Atlantic meridional overturning circulation at $26.5^{\circ} \mathrm{N}$. Science $317,935-938$.

Cunningham, S.A., Christopher, D., Roberts, E.F.-W., Johns, W.E., Hobbs, W., Palmer, M.D., Rayner, D., Smeed, D.A., McCarthy, G., 2013. Atlantic Meridional 
Overturning Circulation slowdown cooled the subtropical ocean. Geophysical Research Letters 40, 6202-6207.

Curry, R., Nobre, C., 2008. HydroBase3. <http://www.whoi.edu/science/PO/ hydrobase/php/index.php>.

Dansgaard, W. Johnsen, S., Clausen, H., Dahl-Jensen, D., Gundestrup, N., Hammer, C., Hvidberg, C., Steffensen, J., Sveinbjörnsdottir, A., Jouzel, J., et al., 1993. Evidence for general instability of past climate from a $250-\mathrm{kyr}$ ice-core record. Nature $364,218-220$

Dee, D., Uppala, S., Simmons, A., Berrisford, P., Poli, P., Kobayashi, S., Andrae, U., Balmaseda, M., Balsamo, G., Bauer, P., et al., 2011. The ERA-Interim reanalysis: configuration and performance of the data assimilation system. Quarterly Journal of the Royal Meteorological Society 137, 553-597.

Ekman, V.W., 1905. On the influence of the earth's rotation on ocean-currents. Arkiv för matematik, astronomi och fysik 2, 1-52.

Frajka-Williams, E., Cunningham, S.A., Bryden, H., King, B.A., 2011. Variability of Antarctic bottom water at $24.5^{\circ} \mathrm{N}$ in the Atlantic. Journal of Geophysical Research 116, C11026.

Garcia, R.F., Meinen, C.S., 2014. Accuracy of Florida Current volume transport measurements at $27^{\circ} \mathrm{N}$ using multiple observational techniques. Journal of Atmospheric and Oceanic Technology 31, 1169-1180.

Haines, K., Stepanov, V.N., Valdivieso, M., Zuo, H., 2013. Atlantic meridional heat transports in two ocean reanalyses evaluated against the RAPID array. Geophysical Research Letters 40, 343-348.

Hall, M.M., Bryden, H.L., 1982. Direct estimates and mechanisms of ocean heat transport. Deep Sea Research Part A: Oceanographic Research Papers 29, 339359.

Hirschi, J., Baehr, J., Marotzke, J., Stark, J., Cunningham, S., Beismann, J.-O., 2003. A monitoring design for the Atlantic meridional overturning circulation. Geophysical Research Letters 30 (7), 1413.

IOC, Scor, IAPSO, 2010. The International Thermodynamic Equation of Seawater 2010: Calculation and Use of Thermodynamic Properties. Intergovernmental Oceanographic Commission, Manuals and Guides No. 56

Johns, W.E., Kanzow, T., Zantopp, R., 2005. Estimating ocean transports with dynamic height moorings: an application in the Atlantic Deep Western Boundary Current at 26 N. Deep Sea Research Part I: Oceanographic Research Papers 52, 1542-1567.

Johns, W., Beal, L., Baringer, M., Molina, J., Cunningham, S., Kanzow, T., Rayner, D., 2008. Variability of shallow and deep western boundary currents off the Bahamas during 2004-05: results from the 26 N RAPID-MOC array. Journal of Physical Oceanography 38, 605-623.

Johns, W.E., Baringer, M.O., Beal, L.M., Cunningham, S.A., Kanzow, T., Bryden, H.L., Hirschi, J.J.M., Marotzke, J., Meinen, C.S., Shaw, B., Curry, R., 2011. Continuous, array-based estimates of Atlantic Ocean heat transport at $26.5^{\circ} \mathrm{N}$. Journal of Climate 24, 2429-2449.

Johnson, G.C., Purkey, S.G., Toole, J.M., 2008. Reduced Antarctic meridional overturning circulation reaches the North Atlantic Ocean. Geophysical Research Letters 35, L22601.

Jung, G.H., 1952. Note on the meridional transport of energy by the oceans. Journal of Marine Research 11, 2.

Kanzow, T., Send, U., Zenk, W., Chave, A.D., Rhein, M., 2006. Monitoring the integrated deep meridional flow in the tropical North Atlantic: long-term performance of a geostrophic array. Deep Sea Research Part I: Oceanographic Research Papers 53, 528-546.

Kanzow, T., Cunningham, S.A., Rayner, D., Hirschi, J.J.-M., Johns, W.E., Baringer, M.O. Bryden, H.L., Beal, L.M., Meinen, C.S., Marotzke, J., 2007. Observed flow compensation associated with the MOC at $26.5^{\circ} \mathrm{N}$ in the Atlantic. Science 317 , 938-941.

Kanzow, T., Johnson, H., Marshall, D., Cunningham, S., Hirschi, J.-M., Mujahid, A. Bryden, H., Johns, W., 2009. Basinwide integrated volume transports in an eddyfilled ocean. Journal of Physical Oceanography 39, 3091-3110.

Kanzow, T., Cunningham, S.A., Johns, W.E., Hirschi, J.J.-M., Marotzke, J., Baringer, M.O., Meinen, C.S., Chidichimo, M.P., Atkinson, C., Beal, L.M., Bryden, H.L., Collins, J., 2010. Seasonal variability of the Atlantic meridional overturning circulation at $26.5^{\circ} \mathrm{N}$. Journal of Climate $23,5678-5698$.

Kent, E.C., Fangohr, S., Berry, D.I., 2013. A comparative assessment of monthly mean wind speed products over the global ocean. International Journal of Climatology 33 (11), 2520-2541.

Longworth, H.R., Bryden, H.L., 2007. Discovery and quantification of the Atlantic meridional overturning circulation: the importance of $25^{\circ} \mathrm{N}$. In: Schmittner, A. Chiang, J.C.H., Hemming, S.R. (Eds.), Ocean Circulation: Mechanisms and Impacts - Past and Future Changes of Meridional Overturning. American Geophysical Union, Washington, DC, pp. 5-18.

Marotzke, J., Giering, R., Zhang, K.Q., Stammer, D., Hill, C., Lee, T., 1999. Construction of the adjoint MIT ocean general circulation model and application to Atlantic heat transport sensitivity. Journal of Geophysical Research: Oceans (19782012) 104, 29529-29547.

McCarthy, G., 2012. RRS Discovery Cruise 382, 08 Oct-24 Nov 2012. RAPID Moorings Cruise Report. National Oceanography Centre Cruise Report 21. National Oceanography Centre, Southampton, UK, 196pp.

McCarthy, G.D., Frajka-Williams, E., Johns, W.E., Baringer, M.O., Meinen, C., Bryden, H.L., Rayner, D., Duchez, A., Cunningham, S.A., 2012. Observed interannual variability of the Atlantic meridional overturning circulation at $26.5^{\circ} \mathrm{N}$. Geophysical Research Letters 39, L19609.

McDonagh, E.L., King, B.A., Bryden, H.L., Courtois, P., Szuts, Z., Baringer, M.O., Cunningham, S.A., Atkinson, C.A., McCarthy, G., 2014. Continuous estimate of
Atlantic oceanic freshwater flux at $26^{\circ} \mathrm{N}$. Journal of Climate, submitted for publication.

McPhaden, M.J., Ando, K., Bourles, B., Freitag, H., Lumpkin, R., Masumoto, Y., Murty, V., Nobre, P., Ravichandran, M., Vialard, J., Vousden, D., Yu, W., 2010. The global tropical moored buoy array. Proceedings of OceanObs 9.

Meinen, C.S., Baringer, M.O., Garcia, R.F., 2010. Florida Current transport variability: an analysis of annual and longer-period signals. Deep Sea Research Part I: Oceanographic Research Papers 57, 835-846.

Meinen, C.S., Speich, S., Perez, R.C., Dong, S., Piola, A.R., Garzoli, S.L., Baringer, M.O. Gladyshev, S., Campos, E.J., 2013. Temporal variability of the meridional overturning circulation at $34.5^{\circ} \mathrm{S}$ : results from two pilot boundary arrays in the South Atlantic. Journal of Geophysical Research: Oceans 85, 154-168.

Millero, F.J., Feistel, R., Wright, D.G., McDougall, T.J., 2008. The composition of Standard Seawater and the definition of the Reference-Composition Salinity Scale. Deep Sea Research Part I: Oceanographic Research Papers $55,50-72$.

Mills, E.L., 2009. Fluid Envelope of Our Planet: How the Study of Ocean Currents Became a Science. University of Toronto Press.

Mittelstaedt, E., 1983. The upwelling area off Northwest Africa - a description of phenomena related to coastal upwelling. Progress in Oceanography 12, 307 331.

Montgomery, R.B., 1974. Seasonal variability of the Florida Current. Journal of Marine Research 32, 533-534.

Msadek, R., Johns, W.E., Yeager, S.G., Danabasoglu, G., Delworth, T.L., Rosati, A. 2013. The Atlantic Meridional Heat transport at $26.5^{\circ} \mathrm{N}$ and its relationship with the MOC in the RAPID array and the GFDL and NCAR coupled models. Journal of Climate 26, 4335-4356.

Purkey, S., Johnson, G., 2012. Global contraction of Antarctic bottom water between the 1980s and 2000s. Journal of Climate 25, 5830-5844.

Rayner, D., Kanzow, T., 2011. The design strategy and methodology of the RAPIDMOC project moorings. Underwater Technology: The International Journal of the Society for Underwater 29, 159-171.

Rayner, D., Cunningham, S., et al., 2005. RRS Discovery Cruises D277/D278: RAPID Mooring Cruise Report: February-March 2004. Southampton Oceanography Centre Cruise Report 53. Southampton Oceanography Centre, Southampton, UK, $103 p p$.

Rayner, D., Hirschi, J.J.-M., Kanzow, T., Johns, W.E., Wright, P.G., Frajka-Williams, E. Bryden, H.L., Meinen, C.S., Baringer, M.O., Marotzke, J., Beal, L.M., Cunningham, S.A., 2011. Monitoring the Atlantic meridional overturning circulation Atlantic meridional overturning circulation. Deep Sea Research Part II: Topical Studies in Oceanography 58, 1744-1753.

Rayner, D. et al., 2014. Comparison of laboratory calibration with ship board calibration of moored CTDs. Journal of Atmospheric and Oceanic Technology, in preparation.

Reynolds, R.W., Smith, T.M., Liu, C., Chelton, D.B., Casey, K.S., Schlax, M.G., 2007. Daily high-resolution-blended analyses for sea surface temperature. Journal of Climate 20, 5473-5496.

Rhines, P., Hakkinen, S., Josey, S.A., 2008. Is the oceanic heat transport significant in the climate system? In: Arctic-Subarctic Ocean Fluxes: Defining the Role of the Northern Seas in Climate. Springer, pp. 111-130.

Richardson, P.L., 2008. On the history of meridional overturning circulation schematic diagrams. Progress in Oceanography 76, 466-486.

Roberts, C.D., Waters, J., Peterson, K.A., Palmer, M., McCarthy, G.D., Frajka-Williams, E., Haines, K., 2013. Atmosphere drives recent interannual variability of the Atlantic meridional overturning circulation at $26.5^{\circ} \mathrm{N}$. Geophysical Research Letters 40 (19), 5164-5170.

Roemmich, D., Gilson, J., 2009. The 2004-2008 mean and annual cycle of temperature, salinity and steric height in the global ocean from the Argo Program. Progress in Oceanography 82, 81-100.

Roemmich, D., Wunsch, C., 1985. Two transatlantic sections: meridional circulation and heat flux in the subtropical North Atlantic Ocean. Deep Sea Research Part A: Oceanographic Research Papers 32, 619-664.

Sea-Bird Electronics, 2014. MicroCAT C-T (P optional) Recorder. <http:// www.seabird.com/products/spec_sheets/37smdata.htm>.

Seager, R, Battisti, D.S., Yin, J., Gordon, N., Naik, N., Clement, A.C. Cane, M.A., 2002. Is the Gulf Stream responsible for Europe's mild winters? Quarterly Journal of the Royal Meteorological Society 128, 2563-2586.

Smeed, D.A., Wright, P.G., 2009. Glider Cruise Report: Bellamite and Dynamite, 15 Sep-24 Nov 2008 and 21 May-21 Jul 2009: RAPID Glider Deployment Report. National Oceanography Centre Southampton Cruise Report 44. Nationa Oceanography Centre, Southampton, UK, 107pp.

Smeed, D.A., McCarthy, G.D., Cunningham, S., Frajka-Williams, E., Rayner, D., Johns, W., Meinen, C., Baringer, M., Moat, B., Duchez, A., et al., 2014. Observed decline of the Atlantic Meridional Overturning Circulation 2004 to 2012. Ocean Science $10,29-38$.

Smith, S.D., 1980. Wind stress and heat flux over the ocean in gale force winds. Journal of Physical Oceanography 10, 709-726.

Srokosz, M., 2004. New experiment deploys observing array in N. Atlantic to investigate rapid climate change. Eos, Transactions American Geophysical Union 85, 78-83.

Sverdrup, H.U., Johnson, M.W., Fleming, R.H., et al., 1942. The Oceans: Their Physics, Chemistry, and General Biology. Prentice-Hall, New York, p. 1087.

Swallow, J., Worthington, L., 1957. Measurements of deep currents in the western North Atlantic. Nature 179, 1183-1184.

Warren, B.A., Wunsch, C., 1981. Deep circulation of the world ocean. In: Evolution of Physical Oceanography. MIT Press. 
Wijffels, S., Firing, E., Bryden, H., 1994. Direct observations of the Ekman balance at $10^{\circ} \mathrm{N}$ in the Pacific. Journal of Physical Oceanography 24, 1666-1679.

Woodgate, R.A., Aagaard, K., Weingartner, T.J., 2005. Monthly temperature, salinity and transport variability of the Bering Strait through flow. Geophysical Research Letters 32, 4.

Worthington, L.V., 1976. On the North Atlantic Circulation 6. Johns Hopkins University Press, Baltimore.
Wunsch, C., 2008. Mass and volume transport variability in an eddy-filled ocean. Nature Geoscience 1, 165-168.

Xu, X., Schmitz, W.J., Hurlburt, H.E., Hogan, P.J., 2012. Mean Atlantic meridional overturning circulation across $26.5^{\circ} \mathrm{N}$ from eddy-resolving simulations compared to observations. Journal of Geophysical Research 117, C3. 